Article

\title{
Mass Spectrometry Reveals Molecular Structure of Polyhydroxyalkanoates Attained by Bioconversion of Oxidized Polypropylene Waste Fragments
}

\author{
Brian Johnston ${ }^{1}$, Iza Radecka ${ }^{1, *(1)}$, Emo Chiellini ${ }^{2}$, David Barsi ${ }^{2}$, Vassilka Ivanova Ilieva ${ }^{2}$, \\ Wanda Sikorska $^{3}$, Marta Musioł ${ }^{3}$, Magdalena Zięba ${ }^{3}$, Paweł Chaber ${ }^{3}$, Adam A. Marek ${ }^{4}$ (D), \\ Barbara Mendrek 1,3, Anabel Itohowo Ekere ${ }^{1}$, Grazyna Adamus ${ }^{3, *(D)}$ and \\ Marek Kowalczuk 1,3,*(D) \\ 1 Wolverhampton School of Biology, Chemistry and Forensic Science, Faculty of Science and Engineering, \\ University of Wolverhampton, Wolverhampton WV1 1LY, UK; B.Johnston@wlv.ac.uk (B.J.); \\ Barbara.Mendrek@wlv.ac.uk (B.M.); I.A.Jonah@wlv.ac.uk (A.I.E.) \\ 2 Laboratorio Materiali Polimerici Ecocompatibili (LMPE), via Nuova, 44/a, Segromigno in Monte, \\ 55018 Capannori (LU), Italy; emo.chiellini@Impe.eu (E.C.); david.barsi@lmpe.eu (D.B.); \\ Vassilka.Ilieva@lmpe.eu (V.I.I.) \\ 3 Centre of Polymer and Carbon Materials, Polish Academy of Sciences, 41-800 Zabrze, Poland; \\ wsikorska@cmpw-pan.edu.pl (W.S.); m.musiol@cmpw-pan.edu.pl (M.M.); \\ mzieba@cmpw-pan.edu.pl (M.Z.); pchaber@cmpw-pan.edu.pl (P.C.) \\ 4 Department of Chemical Organic Technology and Petrochemistry, Silesian University of Technology, \\ 44-100 Gliwice, Poland; adam.a.marek@polsl.pl \\ * Correspondence: I.Radecka@wlv.ac.uk (I.R.); Grazyna.Adamus@cmpw-pan.edu.pl (G.A.); \\ marek.kowalczuk@cmpw-pan.edu.pl (M.K.); Tel.: +48-322-716-077 (ext. 225) (M.K.)
}

Received: 14 August 2019; Accepted: 25 September 2019; Published: 27 September 2019

\begin{abstract}
This study investigated the molecular structure of the polyhydroxyalkanoate (PHA) produced via a microbiological shake flask experiment utilizing oxidized polypropylene (PP) waste as an additional carbon source. The bacterial strain Cupriavidus necator H16 was selected as it is non-pathogenic, genetically stable, robust, and one of the best known producers of PHA. Making use of PHA oligomers, formed by controlled moderate-temperature degradation induced by carboxylate moieties, by examination of both the parent and fragmentation ions, the ESI-MS/MS analysis revealed the 3-hydroxybutyrate and randomly distributed 3-hydroxyvalerate as well as 3-hydroxyhexanoate repeat units. Thus, the bioconversion of PP solid waste to a value-added product such as PHA tert-polymer was demonstrated.
\end{abstract}

Keywords: electrospray ionization dual mass spectrometry (ESI-MS/MS); polyhydroxyalkanoate (PHA); polypropylene (PP); prodegraded; Cupriavidus necator; coral reef; bioplastics; recycling

\section{Introduction}

Mass spectrometry (MS) currently represents a powerful technique for the structural characterization of polymers. Progress in this area is tremendous and covers novel mass spectrometry characterization methods as well as the polymers that have already been analyzed. With a soft ionization technique such as electrospray ionization (ESI), and a reasonable mass accuracy $(<100 \mathrm{ppm})$, single-stage MS can provide information about (co)polymer structures [1]. It may also be helpful in the synthesis of biodegradable polymers from natural and nonrenewable resources [2].

Dual-stage electrospray mass spectrometry (ESI-MS/MS), which exploits the dissociation chemistry of mass-selected ions, has been effectively used to analyze the structures of polymer 
end groups and the sequences of linear copolymers [3]. It is of particular importance in the case of biodegradable polyesters and the polymeric materials made from them due to their potential applications in medicine, the cosmetics industry, agro chemistry, packaging, and environmental protection. In MS/MS studies, mass analysis is performed twice. The parent ion formed in the ion source is mass-selected and its internal energy is raised to induce fragmentation. Among common ion-activation methods, collisionally activated dissociation (CAD) has been preferentially used in our studies [4]. By means of the methodology described by some of us, the random comonomer arrangements have been confirmed in poly(3-hydroxybutyrate-co-3-hydroxyvalerate), (PHBV), and poly(3-hydroxybutyrate-co-3-hydroxyhexanoate), (PHBH), copolymers (contained by two different co-monomeric units) and was also applied to differentiate block from random copolymers $[5,6]$. However, to the best of our knowledge, deeper MS studies of PHA with more than two different repeat units have not been performed until now.

Polypropylene (PP) is the second-most widely manufactured petroleum-based plastic after polyethylene (PE) and some of its applications include polymer banknotes, clothing, bottles, packaging, carpets, and automotive products $[7,8]$. As with many other traditionally produced plastics, PP is cost-effective, lightweight, and strong, however, its highly stable structure makes the process of natural biological degradation difficult [9]. As a result of this, PP production creates a large carbon footprint and due to the short lifespan of packaging, the majority of PP ends up in landfills $[8,10]$. Approximately 8 million tons of mixed plastic ends up in our oceans and coastal areas (Figure 1), and the majority of the floating debris is composed of PP and PE due to their high production volumes and buoyancy [10,11]. During a recent survey of 159 coral reefs in the Asia-Pacific region, it has been estimated that there are approximately 11.1 billion plastic items entangled in the coral, and this figure is expected to rise by 40 percent by 2025 [12]. This plastic waste does not just pose a threat due to its presence by choking or poisoning sea-life, but it can also host pathogens that are now known to be initiators of disease outbreaks across coral reefs [12,13]. PP has even been directly identified as a transporter of pathogenic bacteria related to cholera responsible for white syndromes, diseases that destroy coral tissue [12-15]. The potential use of PP in this study is for its bioconversion into value-added products such as polyhydroxyalkanoates (PHAs), which would leave vital food-related carbon resources untouched.

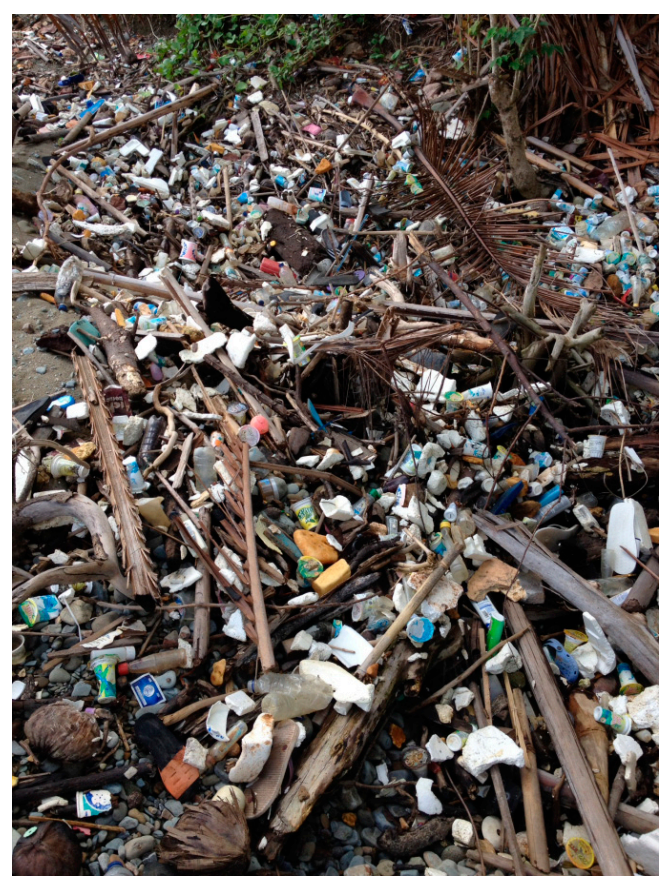

Figure 1. Beach area in Ambon, Indonesia contaminated with plastic waste. Image provided by Chris Mason-Parker. 
PHAs are a family of organic polymers that contain 3-, 4-, 5-, and 6-hydroxyalkanoic acids. They are non-toxic, biocompatible, and most importantly, completely biodegradable, making them a "greener" substitute for common fossil-fuel-based synthetic plastics. PHAs are produced by bacteria and plants naturally from renewable resources [16]. The bacterial strain Cupriavidus necator H16 (formerly Ralstonia eutropha) was selected for this study as it is a reliable synthesizer of PHAs (used as an energy store), it grows well at relatively low temperatures, has some immunity to some heavy metals, and possesses a stable, well-documented genetic profile $[17,18]$. In order to demonstrate PHA production, shake flask experiments were used as they are easily repeatable and provide partial stress conditions through a limited oxygen supply. This limitation can be advantageous as it is already known that some bacteria can accumulate large amounts of PHA under oxygen limitation conditions. A disadvantage of using shake flasks is that conditions monitoring is limited, however, for the purposes of this study, the required parameters were maintained. The oxidatively prodegraded PP fermentation, herein described, could be one way according to which plastic solid waste (PSW) could be recycled for value-added PHA productions [19-21].

While traditional techniques such as gel permeation chromatography (GPC) and nuclear magnetic resonance (NMR) spectroscopy are powerful tools for the structural characterization of PHAs (average across a whole sample), mass spectrometry offers the ability to make absolute mass measurements at a molecular level. Since each co-monomer exhibits different dissociation behavior, fragmentation pathways along the chain usually allow copolymers to be sequenced and dual-stage mass spectrometry (MS/MS) can provide detailed structural information about the repeat unit chemistry, end groups, and backbone topology [22-24].

The ESI-MS/MS structural studies of bacterial PHA copolymers were based on the analysis of their oligomers obtained by alkaline hydrolysis or controlled moderate-temperature degradation induced by carboxylate moieties [25]. Using this approach, oligomers containing carboxylic and olefinic end groups and the same composition and sequence distribution as the starting materials were obtained as revealed by ${ }^{1} \mathrm{H}-\mathrm{NMR}$ and ESI-MS/MS analysis [3]. This relatively rapid approach, developed at our laboratories, has been recently adopted for the automated routine analysis of PHBV copolymers by other authors [26]. In this study, the ESI-MS/MS data acquired enabled the corroboration of whether the obtained PHA copolymers consisted of two (HB and $\mathrm{HV}$ ) or three ( $\mathrm{HB}, \mathrm{HV}$, and $\mathrm{HH})$ co-monomer units randomly distributed or assembled in a block type structure.

\section{Materials and Methods}

\subsection{PP Carbon Source}

The original oxidatively prodegraded PP (PP-0) sample was kindly supplied by the Laboratorio Materiali Polimerici Ecocompatibili (LMPE, Capannori, Italy). The PP film samples contained $1 \%$ by weight of cobalt stearate as pro-oxidant/pro-degradant additive. The sample had a melt flow index (MFI) of $35 \mathrm{~g} / 10 \mathrm{~min}$ at $180{ }^{\circ} \mathrm{C}$ and a density of $0.900 \mathrm{~g} / \mathrm{cm}^{3}$. PP- 0 was then subjected to thermal oxidation and the successful prodegraded samples were designated PP-1 and PP-2, as shown in Figure 2.

The further oxidation treatment was conducted at the Department of Chemical Organic Technology and Petrochemistry, Silesian University of Technology Gliwice, Poland. The PP-0 films (10 g) were placed in a $100 \mathrm{~mL}$ glass-reactor and immersed in a thermal bath $\left(60\right.$ and $\left.80^{\circ} \mathrm{C}\right)$. The process was carried out in a two-phase system: gas-solid phase. Oxygen-ozone mixture $\left(75 \mathrm{mgO}_{3} / \mathrm{L}\right)$ was introduced into the reactor at a flow rate of $7.5 \mathrm{~L} / \mathrm{h}$ and the overall duration of the processes was $20 \mathrm{~h}$. The basic property of the oxidized products was the acid number (AN), which was determined according to PN-EN ISO 2114:2002 standard "Plastics (polyester resins) and paints and varnishes (binders)-Determination of partial acid value and total acid value". The PP-0 to 2 structural details can be found in Sections 3.1-3.3. 

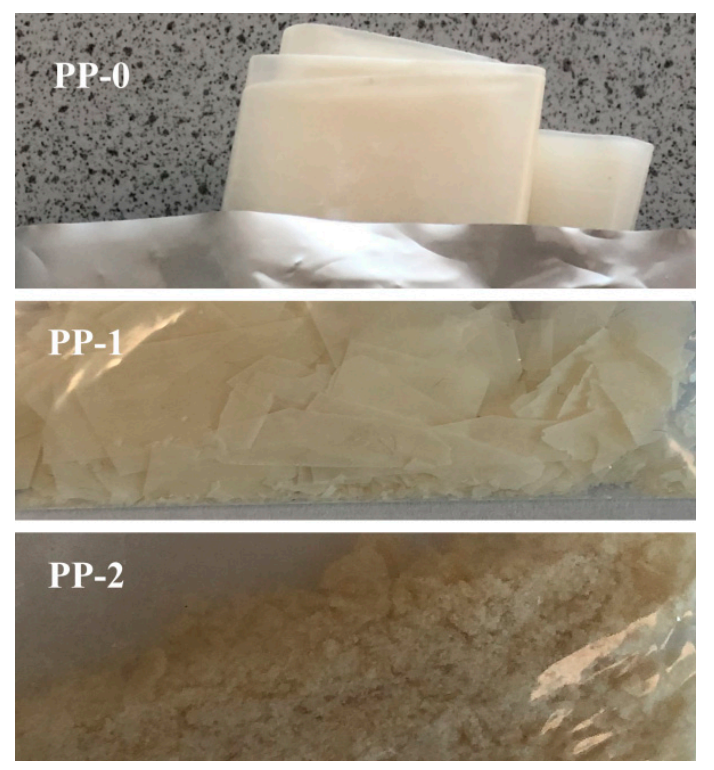

Figure 2. Images of the polypropylene (PP) samples used as additional carbon sources for polyhydroxyalkanoate (PHA) production. PP-0 was the original sample received and PP-1 and PP-2 were treated thermally.

\subsection{Selected Microorganism}

The species of bacteria used was C. necator H16 (NCIMB 10442, ATCC 17699). This organism was obtained from the University of Wolverhampton culture storage facility where it was freeze-dried at $-20^{\circ} \mathrm{C}$. Cultures were revived and grown at $30^{\circ} \mathrm{C}$ in nitrogen-rich tryptone soya broth (TSB) media at $150 \mathrm{rpm}$. The strain was later sub-cultured onto tryptone soya agar (TSA) in Petri dishes and incubated at the standard optimal temperature for $C$. necator $\left(30^{\circ} \mathrm{C}\right)$ for $24 \mathrm{~h}$. At this point, the strain was ready for use to inoculate microbial experiments in TSB and nitrogen-limited, basal salts media (BSM) during fermentations of $48 \mathrm{~h}$.

\subsection{Growth Media and Chemicals}

The TSB and TSA for bacterial growth were purchased from Lab M Ltd. (Lancashire, UK). Both of these growth media were prepared using aseptic techniques under standard conditions. The BSM used consisted of distilled water, $1 \mathrm{~g} / \mathrm{L} \mathrm{K}_{2} \mathrm{HPO}_{4}, 1 \mathrm{~g} / \mathrm{L} \mathrm{KH}_{2} \mathrm{PO}_{4}, 1 \mathrm{~g} / \mathrm{L} \mathrm{KNO} 3,1 \mathrm{~g} / \mathrm{L}\left(\mathrm{NH}_{4}\right)_{2} \mathrm{SO}_{4}, 0.1 \mathrm{~g} / \mathrm{L}$ $\mathrm{MgSO}_{4} 7 \mathrm{H}_{2} \mathrm{O}, 0.1 \mathrm{~g} / \mathrm{L} \mathrm{NaCl}$, and $10 \mathrm{~mL} / \mathrm{L}$ of a trace element solution that contained $2 \mathrm{mg} / \mathrm{L} \mathrm{CaCl} 2,2 \mathrm{mg} / \mathrm{L}$ $\mathrm{CuSO}_{4} 5 \mathrm{H}_{2} \mathrm{O}, 2 \mathrm{mg} / \mathrm{L} M n \mathrm{SO}_{4} 5 \mathrm{H}_{2} \mathrm{O}, 2 \mathrm{mg} / \mathrm{L} \mathrm{ZnSO}{ }_{4} 5 \mathrm{H}_{2} \mathrm{O}, 2 \mathrm{mg} / \mathrm{L} \mathrm{FeSO}_{4}$, and $2 \mathrm{mg} / \mathrm{L}\left(\mathrm{NH}_{4}\right)_{6} \mathrm{Mo}_{7} \mathrm{O}_{24}$ $4 \mathrm{H}_{2} \mathrm{O}$. The BSM salts used were obtained from BDH Chemicals Ltd. (Poole, UK). The Ringer's solution used throughout the study was purchased from Lab M Ltd. (Lancashire, UK). A 1/4 strength tablet was added to $500 \mathrm{~mL}$ of deionized water and dissolved for regular colony counting (Section 2.4). All of the media mentioned were autoclaved (Priorclave Ltd., London, UK) at $121^{\circ} \mathrm{C}$ for $15 \mathrm{~min}$. From $25 \mathrm{~mL}$ starter flasks of TSB grown at $30^{\circ} \mathrm{C}, 1 \mathrm{~mL}$ of inocula were dropped into $250 \mathrm{~mL}$ TSB media conical flasks to establish a narrow starting range of CFUs for comparison.

\subsection{Shake Flask Procedure}

Starter cultures were prepared using $20 \mathrm{~mL}$ TSB (in $50 \mathrm{~mL}$ flasks). These flasks were inoculated with single $C$. necator colonies from TSA spread plates. Those cultures were then incubated (aerobically) for $24 \mathrm{~h}$ at $30^{\circ} \mathrm{C}$ at $150 \mathrm{rpm}$, in a rotary incubator (Incu-Shake MIDI, Shropshire, UK). After $24 \mathrm{~h}$, these cultures were checked for contamination by standard Gram staining and microscope techniques. Shake flask experimentation was performed in triplicate using $500 \mathrm{~mL}$ wide neck Erlenmeyer flasks. Each flask had $1 \mathrm{~g}$ of the appropriate PP sample, that was first put into a $100 \mathrm{~mL}$ beaker and sonicated 
(in $50 \mathrm{~mL}$ of the appropriate media) for $8 \mathrm{~min}$ at 0.5 active and passive intervals with a power of 70\% using a Bandelin Electronic sonicator (Berlin, Germany) to form an emulsion of either TSB/PP-0 to 2 or BSM/PP-0 to 2 . This emulsion was then sampled for sterility by spread plating. The sterile emulsion was then added to $200 \mathrm{~mL}$ of sterile TSB or BSM in a $500 \mathrm{~mL}$ flask, followed by $1000 \mu \mathrm{L}$ of the starter culture, giving a total volume of $250 \mathrm{~mL}$ and an equal concentration of bacteria for comparison. The experimental control was $200 \mathrm{~mL}$ TSB or BSM, inoculated with $1000 \mu \mathrm{L}$ of starter culture with no PP samples. The flasks were incubated in a rotary incubator under the standard growth conditions for C. necator for $48 \mathrm{~h}$.

The viable cell counts were undertaken using the techniques of Miles and Misra [27]. In summary, $5 \mathrm{~mL}$ samples were aseptically collected from flask cultures at $0,3,24,27$, and $48 \mathrm{~h}$. Each sample was serially diluted from $10^{-1}$ to $10^{-9}$ and then $20 \mu \mathrm{L}$ of each dilution was pipetted onto sectioned TSA plates in triplicate. These plates were then incubated at $30^{\circ} \mathrm{C}$ for $48 \mathrm{~h}$ and the colonies were counted and expressed in $\log 10 \mathrm{CFU} \mathrm{mL} \mathrm{mL}^{-1}$ (Section 3.4).

\subsection{PHA Extraction Method}

A $48 \mathrm{~h}$ shake flask period was found to give optimum PHA yield. Flasks were removed from their incubators and their contents were filtered with a sieve to remove PP residue material. The filtrate was then divided into tubes and centrifuged in a Sigma 6-16KS centrifuge for $10 \mathrm{~min}$ at room temperature at $4500 \mathrm{rpm}$. The supernatant was discarded and the biomass pellet was frozen overnight at $-20^{\circ} \mathrm{C}$. The biomass was then lyophilized in an Edwards freeze-drier (Modulyo, Crawley, UK) for a $48 \mathrm{~h}$ period at $-40{ }^{\circ} \mathrm{C}$ and 5 mbar. The dried-out biomass was then carefully weighed and recorded as cell dry weight (CDW). For extraction, the sample was placed inside a thimble closed with cotton (to serve as a filter) and using Soxhlet extraction, HPLC grade chloroform was heated to $47-50{ }^{\circ} \mathrm{C}$ for $48 \mathrm{~h}$. The PHA removed from the biomass was collected as a chloroform/biopolymer mixture. Rotation evaporation $\left(\right.$ at $50^{\circ} \mathrm{C}$ ) was used to remove any chloroform from the round bottom flask. Biopolymer precipitation using $n$-hexane was used in a $250 \mathrm{~mL}$ round-bottom flask and then this was separated with filtration (using Whatman No. 1 paper, Whatman Laboratory, Maidstone, Kent, UK). The final PHA sample was then left in a sterile fume cupboard for drying and the yield was recorded using the following formula:

Percentage yield $=[($ weight of extracted polymer $) /($ dry cell biomass weight $)] \times 100$

\subsection{Characterization Methods}

\subsubsection{GPC Analysis}

The molar mass and molar mass distribution of the PP samples were determined by gel permeation chromatography (GPC, Agilent Technologies PL GPC 220) apparatus equipped with two columns: Agilent PLgel Olexis guard plus 3x Olexis, $30 \mathrm{~cm}, 13 \mu \mathrm{m}$, at $160{ }^{\circ} \mathrm{C} .1,2,4$-Trichlorobenzene with anti-oxidant was employed as a solvent at a flow rate of $1.0 \mathrm{~mL} / \mathrm{min}$. The data were analyzed using polystyrene calibration.

The GPC experiments for the PHA-PP samples studied were conducted in a chloroform solution at $35^{\circ} \mathrm{C}$ at a flow rate of $1 \mathrm{~mL} / \mathrm{min}$ using a Viscotek VE 1122 solvent delivery system with two Mixed C PL-gel styragel columns in series and a Shodex SE 61 refractive index detector. A volume of $10 \mu \mathrm{L}$ of sample solutions in $\mathrm{CHCl}_{3}$ (concentration $0.5 \% \mathrm{~m} / \mathrm{v}$ ) was injected into the system. Polystyrene standards with low dispersity were used to generate a calibration curve.

\subsubsection{FTIR Analysis}

Fourier-transform infrared spectroscopy (FTIR) was used to record the absorbance spectra at an accumulation setting of 64 scans, with a JASCO ATR attachment. The PP-0 (original) sample and the further oxidized PP-1 and PP-2 samples as well as the PHAs from each shake flask experiment (designated PHA-PP-x, where $x$ represents the number of prodegraded and oxidized PP sample utilized), were evaluated. Samples were analyzed as they were received in each case. 


\subsubsection{NMR Analysis}

Proton nuclear magnetic resonance $\left({ }^{1} \mathrm{H}-\mathrm{NMR}\right)$ spectra of PHA-PP samples were recorded using a Bruker-Advance spectrometer (Bruker, Rheinstetten, Germany) operating at $600 \mathrm{MHz}$ with Bruker TOPSPIN 2.0 software, using $\mathrm{CDCl}_{3}$ as the solvent and tetramethylsilane (TMS) as the internal standard. Spectra were obtained with 64 scans, an $11 \mu$ s pulse width, and a $2.66 \mathrm{~s}$ acquisition time. The chemical compositions of samples after thermal degradation were calculated from the integration of signals of methyl groups received from 3-HB at $1.28 \mathrm{ppm}$ and 3-HA $(\mathrm{HV}$ and $\mathrm{HH})$ at $0.9 \mathrm{ppm}$.

\subsubsection{TGA Characterization}

Thermal gravimetric analysis (TGA) was performed with a TGA/DSC1 Mettler-Toledo thermal analyzer at a heating rate of $10^{\circ} \mathrm{C} \mathrm{min}-1$ in a stream of nitrogen $(60 \mathrm{~mL} / \mathrm{min})$ from 25 to $600{ }^{\circ} \mathrm{C}$. The obtained TGA data were analyzed with the Mettler-Toledo Star System SW 9.30. The PHA-PP-x samples were evaluated.

\subsubsection{PHA Characterization at the Molecular Level by ESI-MS/MS}

PHA oligomers for the ESI-MS/MS analyses were obtained via the partial thermal degradation of PHA obtained from shake flask experiments with PP-0, PP-1, and PP-2 samples with TSB, as described above. The partial degradation was performed by controlled moderate-temperature degradation induced by carboxylate in the presence of potassium hydrogen carbonate, $\mathrm{KHCO}_{3}$, as described by Johnston et al. $[17,28]$. The respective amount of polyester and salt, at a ratio $\mathrm{PHA} / \mathrm{KHCO}_{3}$ equal to 5, was introduced in a vial with ethanol and then the mixture was stirred for $30 \mathrm{~min}$ to create a homogeneous suspension that was kept in an oven at $180^{\circ} \mathrm{C}$ for $1 \mathrm{~h}$. After partial thermal degradation, the oligomers were purified with Dowex ${ }^{\circledR} 50 \mathrm{WX} 4$ (hydrogen form; $1: 1 \mathrm{wt} \%$ ). The oligomer was dissolved in chloroform and the mixture was stirred for $4 \mathrm{~h}$. Then, the Dowex ${ }^{\circledR}$ was removed by filtration. The structure at the molecular level of the oligomer samples derived from PHA PP-0 and PHA PP-2 were determined by ESI-MS/MS.

Electrospray ionization mass spectrometry (ESI-MS/MS) analysis was performed using a Thermo Fisher ion trap mass spectrometer (Thermo Fisher Scientific Inc., San Jose, CA, USA). The samples after thermal degradation were dissolved in a water/methanol $(1: 1 ; \mathrm{v} / \mathrm{v})$ or chloroform/methanol (1:1) system. The solutions were introduced to the ESI source by continuous infusion using the instrument syringe pump at a rate of $7 \mu \mathrm{L} / \mathrm{min}$. The ESI source of the LCQ was operated at $4.5 \mathrm{kV}$ and the capillary heater was set to $200^{\circ} \mathrm{C}$. Nitrogen was used as the nebulizing gas. For the ESI-MS/MS experiments, mass-selected mono-isotopic parent ions were isolated and trapped and collisionally activated using helium damping gas, present in the mass analyzer. Each analysis was performed in the positiveion mode.

\section{Results}

\subsection{Characterization of PP Carbon Source - Acid Number (AN)}

The prodegraded PP-0 sample was titrated and found to have an AN of 14.8, which was compared to the thermally treated samples (Table 1). In all cases, the treated samples had higher AN values and therefore more hydrophilic properties $(\mathrm{O}-\mathrm{H}, \mathrm{C}=\mathrm{O}$ groups). By only using ozone, rather than initiators or catalysts, the chance of introducing contaminants was reduced. Using this thermal treatment, the AN of PP- 1 to 2 was managed by temperature.

In Table 1, the conditions of the ox-degradation process and titrations with $\mathrm{KOH}$ to confirm AN 14.8-84.2, can be seen. To analyze the nature of the oxidized groups in more detail, FTIR was applied. The increase in acid number after oxidation treatments indicated the presence of aldehyde, ketone, or carboxylic acid groups $[17,20]$. 
Table 1. Acid number (AN) and conditions used for the thermal degradation of PP-0 to 2 .

\begin{tabular}{ccc}
\hline Sample & AN $[\mathbf{m g ~ K O H} / \mathbf{g}]$ & Process Conditions \\
\hline PP-0 & 14.8 & $\mathrm{~N} / \mathrm{A}$ \\
PP-1 & 84.2 & $80{ }^{\circ} \mathrm{C}, \mathrm{O}_{3} / \mathrm{O}_{2}$, \\
& $20 \mathrm{~h}$ \\
PP-2 & 66.3 & $100{ }^{\circ} \mathrm{C}, \mathrm{O}_{3} / \mathrm{O}_{2}$, \\
& & $20 \mathrm{~h}$ \\
\hline
\end{tabular}

\subsection{FTIR Analysis of PP Carbon Sources}

The FTIR spectra of the PP-0 sample shown in Figure 3 revealed the following: methyl group $\left(-\mathrm{CH}_{3}\right)$ absorbances can be seen at $2970 \mathrm{~cm}^{-1}$ and at $2910 \mathrm{~cm}^{-1}$; methylene groups $\left(-\mathrm{CH}_{2}-\right)$ at $2870 \mathrm{~cm}^{-1}$; $\left(-\mathrm{CH}_{2}-\right)$ at $2840 \mathrm{~cm}^{-1} ;\left(-\mathrm{CH}_{2}-\right)$ at $1460 \mathrm{~cm}^{-1}$; and $\left(-\mathrm{CH}_{3}\right)$ at $1370 \mathrm{~cm}^{-1}$. These results closely match the observations of Barbes et al. [29]. A relatively strong absorption band with a maximum around $1720 \mathrm{~cm}^{-1}$, corresponding to the stretching vibrations of $\mathrm{C}=\mathrm{O}$ groups, was observed in the spectrum of the PP-1 and PP-2 samples. The appearance of the carbonyl band in the FTIR spectrum of the PP-1 and PP-2 sample was associated with the presence of carboxylic acid, aldehyde, ketone, or ester groups that arose during the thermal oxidation of the plain PP-0 sample. Additionally, in the PP-1 and PP-2 samples, higher absorption bands, characteristic of the hydroxyl groups, were observed at the region of $1100-1200 \mathrm{~cm}^{-1}$ and at $3200-3400 \mathrm{~cm}^{-1}$.

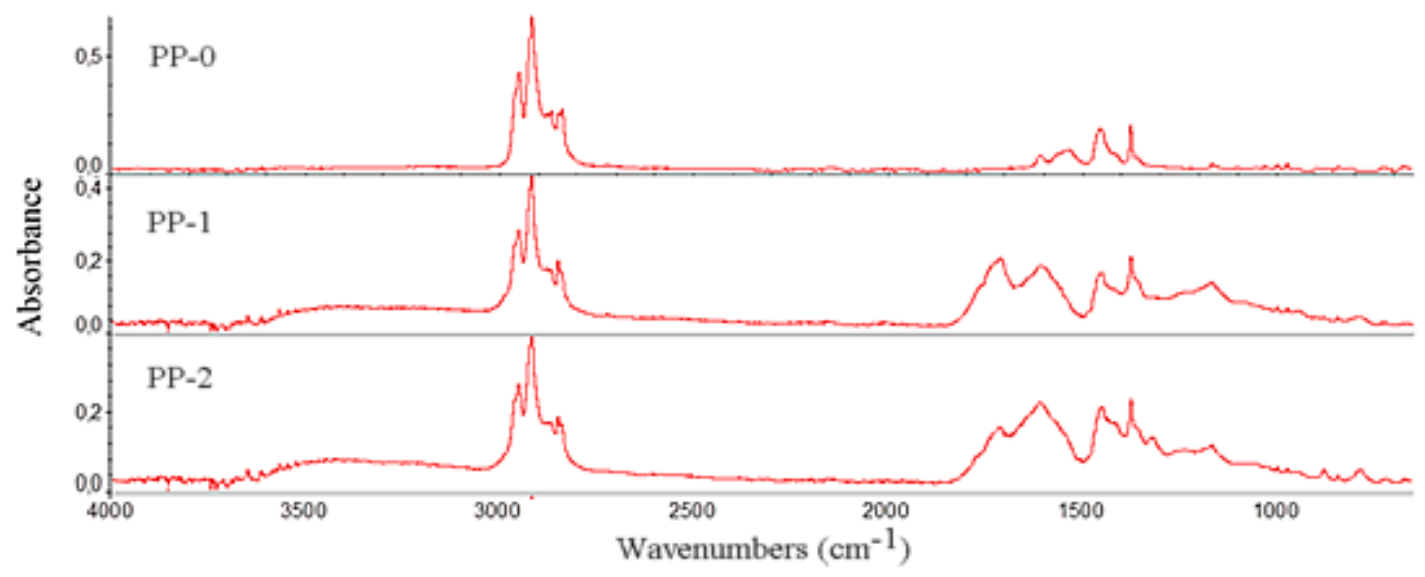

Figure 3. Fourier-transform infrared spectroscopy (FTIR) spectra of samples PP-0 to 2.

Thus, the FTIR spectra show that the increased intensity of $\mathrm{OH}$ and $\mathrm{C}=\mathrm{O}$ groups in the PP- 1 and PP-2 samples further increased the hydrophilicity of these samples in comparison to the PP-0 sample. This variation in intensity is expected to make the PP-1 and PP-2 samples more compatible with the organism and more susceptible to microbial attack than the PP-0 sample. The FTIR results also seem to confirm the titration results in Table 2, where PP- 1 and PP-2 had higher AN values than PP- 0 and therefore were comparatively more hydrophilic carbon sources than the original.

Table 2. The weight average molar mass $\left(M_{\mathrm{W}}\right)$, number average molar mass $\left(M_{\mathrm{n}}\right)$ and dispersity index $(D I)$ of the PP-0 to 2 samples used in this study.

\begin{tabular}{cccc}
\hline Sample & $\boldsymbol{M}_{\boldsymbol{w}}$ & $\boldsymbol{M}_{\boldsymbol{n}}$ & $\boldsymbol{D I}\left(\boldsymbol{M}_{\mathrm{w}} / \boldsymbol{M}_{\boldsymbol{n}}\right)$ \\
\hline PP-0 & 148,000 & 18,000 & 8.2 \\
PP-1 & 12,000 & 2200 & 5.2 \\
PP-2 & 4000 & 1600 & 2.6 \\
\hline
\end{tabular}




\subsection{GPC Analysis of the PP Carbon Sources}

The oxidation of the PP samples appears to have caused a partial degradation of the polymers, resulting in a general decrease in the weight average molar mass $\left(M_{\mathrm{w}}\right)$ (Table 2). The molar mass dispersity index $(D I)$ of the samples was calculated by the $M_{\mathrm{w}}$ and the number average molar mass $\left(M_{n}\right)$ ratio. For the PP-1 sample, there was clearly a reduction of DI from PP-0. The PP-2 DI value was the lowest, showing the most uniform system.

\subsection{Bacteria Growth}

The shake flask experiment of $C$. necator in the nitrogen-rich TSB media is shown in Figure 4 over a $48 \mathrm{~h}$ period with and without the PP-0 and the pretreated samples PP-1 to 2 along with the TSB and BSM controls. A parallel set of experiments with BSM and PP0 to 2 was also conducted, however, the minimal salts showed very little growth like that shown by the BSM controls, and they produced no PHA. These BSM shake flask results were similar to Johnston et al. [20] where pretreated polystyrene fragments were used as carbon sources, however, in this study, the cell biomass was even less.

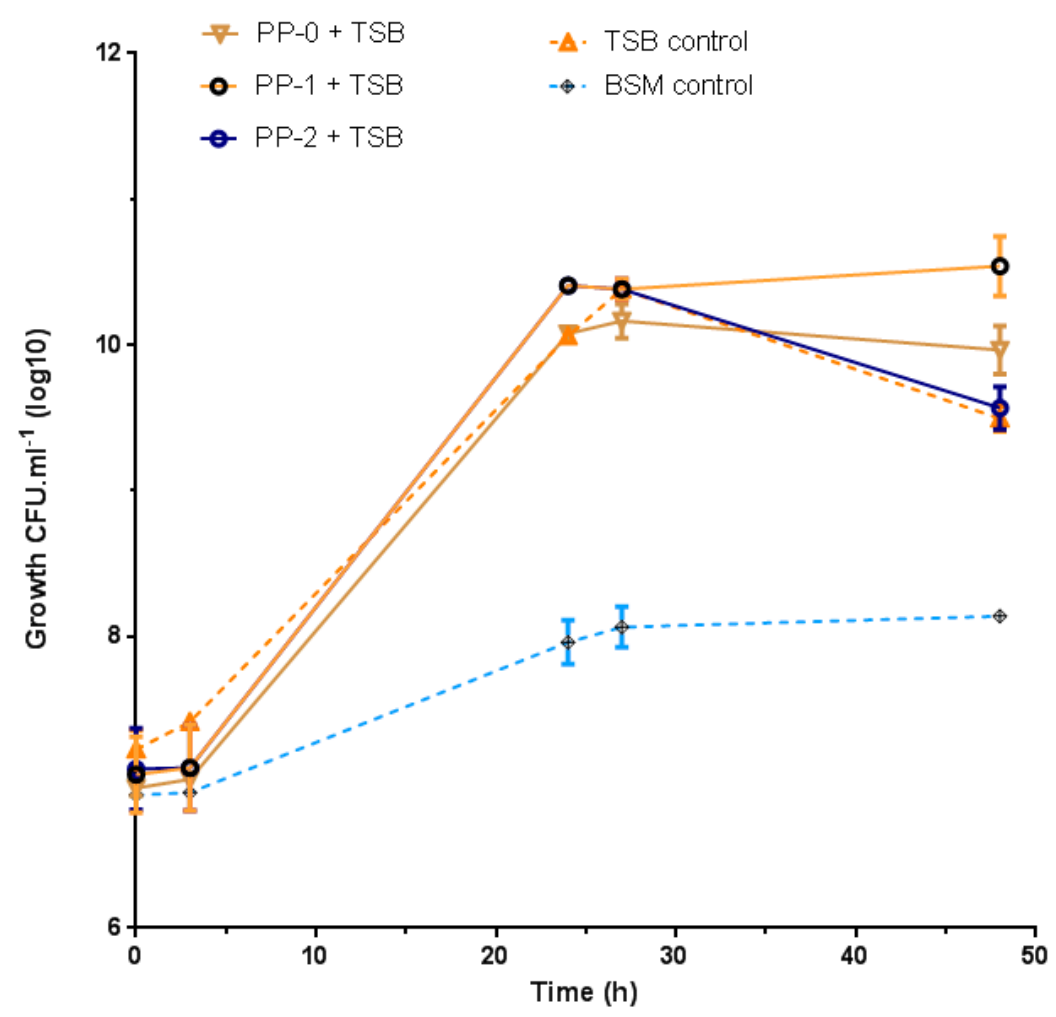

Figure 4. The shake flask experiments of $C$. necator in growth nitrogen-rich tryptone soya broth (TSB) media, with polypropylene (PP) 0 to 2) and basal salts media (BSM) and TSB only controls for comparison. The experiments were conducted over a $48 \mathrm{~h}$ period at $150 \mathrm{rpm}$. Each point is an arithmetic mean of triplicates, while error bars denote the SE of the mean.

The starting CFU numbers of the cultures were between 6.9 and $7.4 \log 10 \mathrm{CFU} / \mathrm{mL}$. A 2-way multiple ANOVA and Tukey's multiple comparison showed that there was a significant difference between the control BSM and all of the TSB + PPx as expected $(<0.0001)$.

When the growth was compared to the TSB control, PP-1 had a P-Value of 0.0352, while PP-2 was not significant (P-Value of $>0.9999$ ). A possible reason for the PP-1 fragments having the highest growth could be that it also possessed an AN value of 84.2 , making it the most hydrophilic additional carbon source. The relative size of the fragments could also provide a platform for some bacterial colonies. PP-0 had the lowest AN, however, it had a relatively strong growth of $3 \log 10 \mathrm{CFU} / \mathrm{mL}$ CFUs, again this could be due to having the largest surface area with PP sheets, rather than PP fragment 
metabolism as its P-Value was not significant compared to the TSB control. PP-0 also had a similar PHA yield to TSB. The PP-1 shake flask analysis with TSB had the highest yield at $42 \%$, while PP-2 and PP-0 (under nitrogen-rich conditions) had similar PHA yields to each other in Table 3.

Table 3. The percentage yield of PHA synthesized by C. necator using $2 \mathrm{~g} / \mathrm{L}$ PP conducted over a $48 \mathrm{~h}$ period at $30^{\circ} \mathrm{C}(150 \mathrm{rpm}) . \mathrm{ND}=$ non-detected; $\mathrm{CDW}=$ cellular dry weight.

\begin{tabular}{cccc}
\hline Media & Average CDW $(\mathrm{g} / \mathrm{L})$ & Average PHA $(\mathrm{g} / \mathrm{L})$ & PHA $(\% w / w)$ \\
\hline BSM only & $0.09 \pm 0.10$ & $\mathrm{ND}$ & $\mathrm{ND}$ \\
TSB only & $2.18 \pm 0.20$ & $0.48 \pm 0.06$ & $22 \%$ \\
PP-0 + BSM & $0.07 \pm 0.03$ & $\mathrm{ND}$ & $\mathrm{ND}$ \\
PP-0 + TSB & $2.26 \pm 0.06$ & $0.58 \pm 0.02$ & $26 \%$ \\
PP-1 + TSB & $3.22 \pm 0.10$ & $1.36 \pm 0.20$ & $42 \%$ \\
PP-2 + TSB & $2.82 \pm 0.10$ & $0.78 \pm 0.02$ & $28 \%$ \\
\hline
\end{tabular}

\subsection{PHA Identification and Characterization}

\subsubsection{NMR, FTIR, GPC, and Thermal Analysis of PHA}

The ${ }^{1} \mathrm{H}-\mathrm{NMR}$ spectra of PHA-PPx (Figure 5) revealed the presence of characteristic signals corresponding to the protons of methyl groups of 3-hydroxybutyrate (3-HB) and 3-hydroxyalkanoate (3-HA) repeating units at $1.28 \mathrm{ppm}$ and $0.9 \mathrm{ppm}$, respectively.

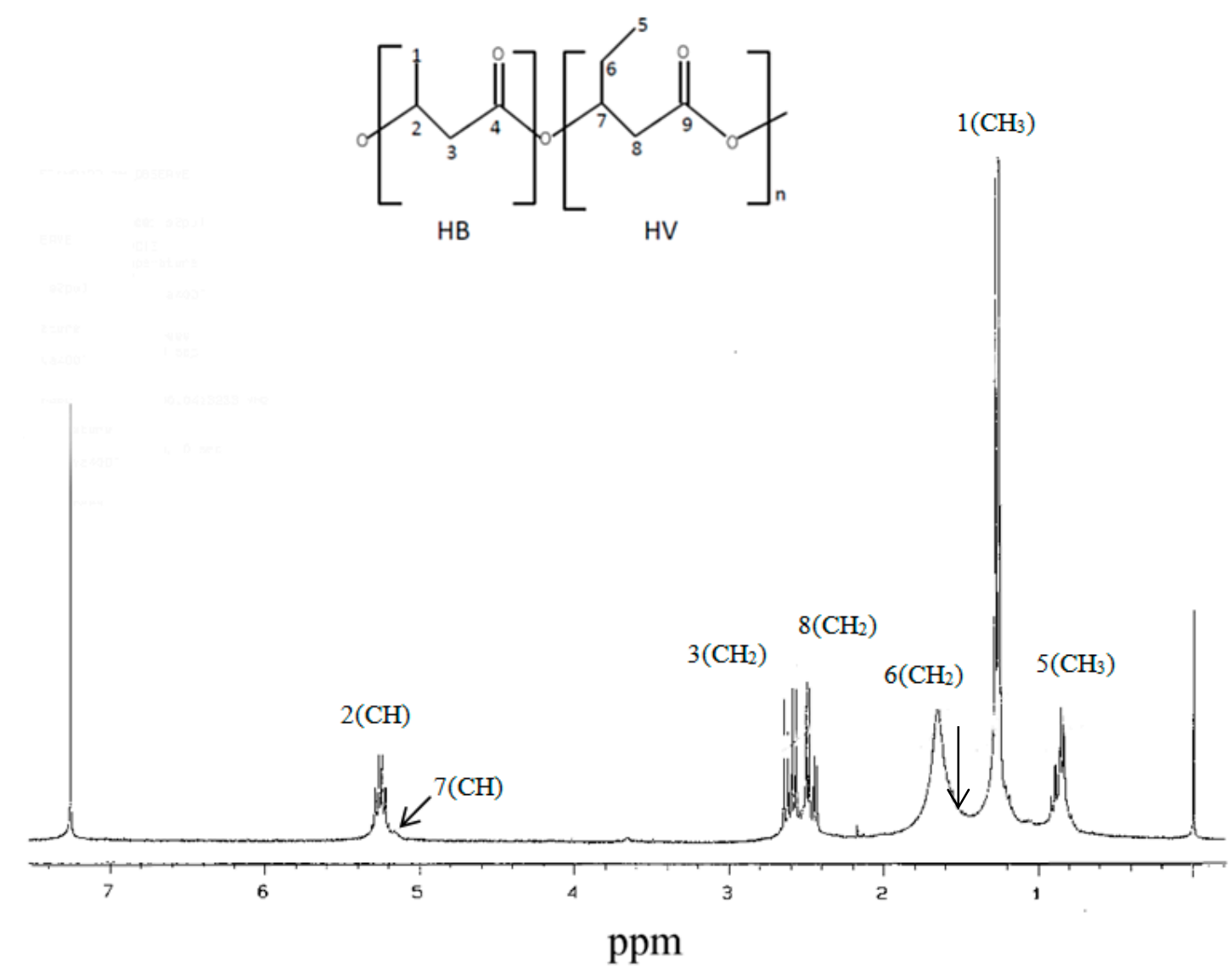

Figure 5. ${ }^{1} \mathrm{H}-\mathrm{NMR}$ of PHAs produced by C. necator from TSB with the PP-2 sample as an additional carbon source.

The FTIR spectra of the PHA samples produced from the PP carbon source (data not shown) upon comparison to the previous FTIR absorbance spectra of PP (Figure 3) cannot exclude the contamination of the PHA with PP fragments. The characteristic peaks for PP (methyl and methylene groups) in the 
range of $2840-2970 \mathrm{~cm}^{-1}$ as well as the peaks shown over $600-1500 \mathrm{~cm}^{-1}$ (which correspond to the C-C aliphatic bonds recorded by Shamala et al. [30]) could be overlapped within the ones of PHA structure.

GPC analysis was used to estimate the molar mass of the obtained biopolymers synthesized by the bacterial shake flask experiments (Table 4). For the sample of PHA-PP-2, the second fraction of lower molar mass was also visible (Figure 6).

Table 4. The GPC results of the PHA-PPx samples produced after $48 \mathrm{~h}$ in shake flask analysis with PP-0 to 2 as additional carbon sources.

\begin{tabular}{cccc}
\hline Sample Name & $\mathbf{M}_{\mathbf{w}}$ & $\mathbf{M}_{\mathbf{n}}$ & DI \\
\hline PHA-PP-0 & 410,000 & 139,000 & 2.9 \\
PHA-PP-1 & 676,000 & 221,000 & 3.0 \\
PHA-PP-2 & 710,000 & 259,000 & 2.7 \\
\hline
\end{tabular}

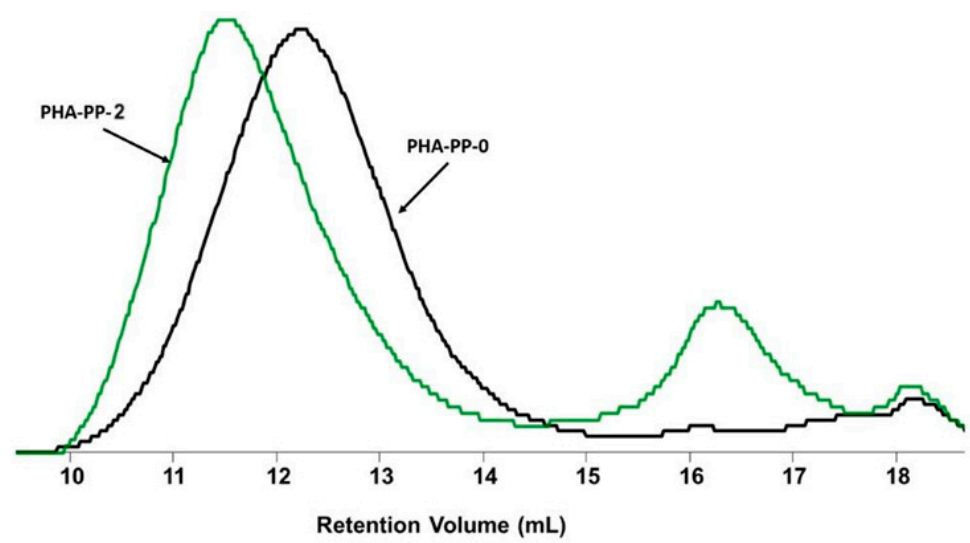

Figure 6. The comparison of the GPC traces of PHA samples produced from PP-0 and PP-2 with TSB by C. necator after $48 \mathrm{~h}$.

The thermal decompositions of PHA produced from the PHA-PP-0 to PP-2 underwent two stages of mass loss. The GPC results suggest that some residue, after the first step of the thermal decomposition of the PHA-PP-2 sample, contained not only PHAs but also PP fragments that survived the post-shake flask process (Table 5) and decomposed at $444.1^{\circ} \mathrm{C}$.

Table 5. Thermogravimetric parameters for PHA samples produced after $48 \mathrm{~h}$ shake flask procedures with PP samples utilized as additional carbon sources in TSB media.

\begin{tabular}{ccccc}
\hline Sample name & \multicolumn{2}{c}{ Step 1 } & \multicolumn{2}{c}{ Step 2 } \\
\hline & $\mathbf{T}_{\max }\left({ }^{\circ} \mathbf{C}\right)$ & Weight loss $(\%)$ & $\mathbf{T}_{\max }\left({ }^{\circ} \mathbf{C}\right)$ & Weight loss (\%) \\
PHA-PP-0 & 291.4 & 86.6 & - & 97.3 \\
PHA-PP-1 & 294.7 & 88.3 & - & 98.7 \\
PHA-PP-2 & 294.2 & 71.6 & 444.1 & 97.7 \\
\hline
\end{tabular}

\subsubsection{Structural Characterization of PHA with Dual-Stage ESI-MS}

The structural characterization (including co-monomer composition and distribution) of biodegradable PHA copolymers was determined with the aid of dual-stage electrospray mass spectrometry (ESI-MS/MS) based on the analysis of the oligomers formed via controlled, partial thermal degradation. Using this method, the uniform PHA oligomers terminated by unsaturated and carboxyl end groups were obtained $[5,28,31,32]$. The chemical composition of partially degraded PHA copolymers was determined from ${ }^{1} \mathrm{H}-\mathrm{NMR}$ spectra (data not shown). The obtained results revealed that the content of co-monomeric units in PHA oligomers was the same as that of the original PHA sample. 
Figure 7 presents the positive ion ESI-MS spectrum of oligomers formed after partial thermal degradation of sample PHA-PP-0. Due to the high affinity of PHA oligomers toward alkali metals (especially to the sodium), the ESI mass spectrum of these oligomers showed a distribution of singly charged sodium adducts of the individual PHA oligomer chains (composed with HB, HV and/or $\mathrm{HH}$ units) terminated by unsaturated and carboxylic end groups with general chemical structures shown in Scheme 1. The signals present in the mass spectrum were grouped in numerous clusters (Figure $7 \mathrm{~b}$ ) due to their different degrees of oligomerization and composition. The differences in the experimental values of $\mathrm{m} / \mathrm{z}$ between the most intensive ions in the neighboring groups of peaks were about $86 \mathrm{Da}$. This corresponds to the molar mass of the HB unit. The mass difference between the neighboring signals within the clusters was equal to $14 \mathrm{Da}$, which corresponds to the difference between the molar mass of (differing with the length of side chains) the 3-hydroxyhexanoate ( $\mathrm{HH}, 114 \mathrm{Da}$ ), 3-hydroxyvalerate ( $\mathrm{HV}, 100 \mathrm{Da})$, and 3-hydroxybutyrate (HB, $86 \mathrm{Da})$ co-monomeric units. The signals belonging within the individual clusters, appearing regularly in the mass spectrum, respectively at $\mathrm{m} / \mathrm{z}$ $=(\mathrm{n} \times 86+23), m / z=((\mathrm{n}-1) \times 86+100+23)$, and $m / z=((\mathrm{n}-1) \times 86+114+23)$ or $m / z=((\mathrm{n}-2) \times 86+2 \times$ $100+23)$ represent sodium adducts of linear $3 \mathrm{HB}, 3-\mathrm{HB} / 3 \mathrm{HV}$ or $3-\mathrm{HB} / 3 \mathrm{HH}$ oligomers terminated by unsaturated and carboxylic end groups. The compositions of the ions belonging to the most intense clusters are assigned in Figure $7 \mathrm{~b}$.

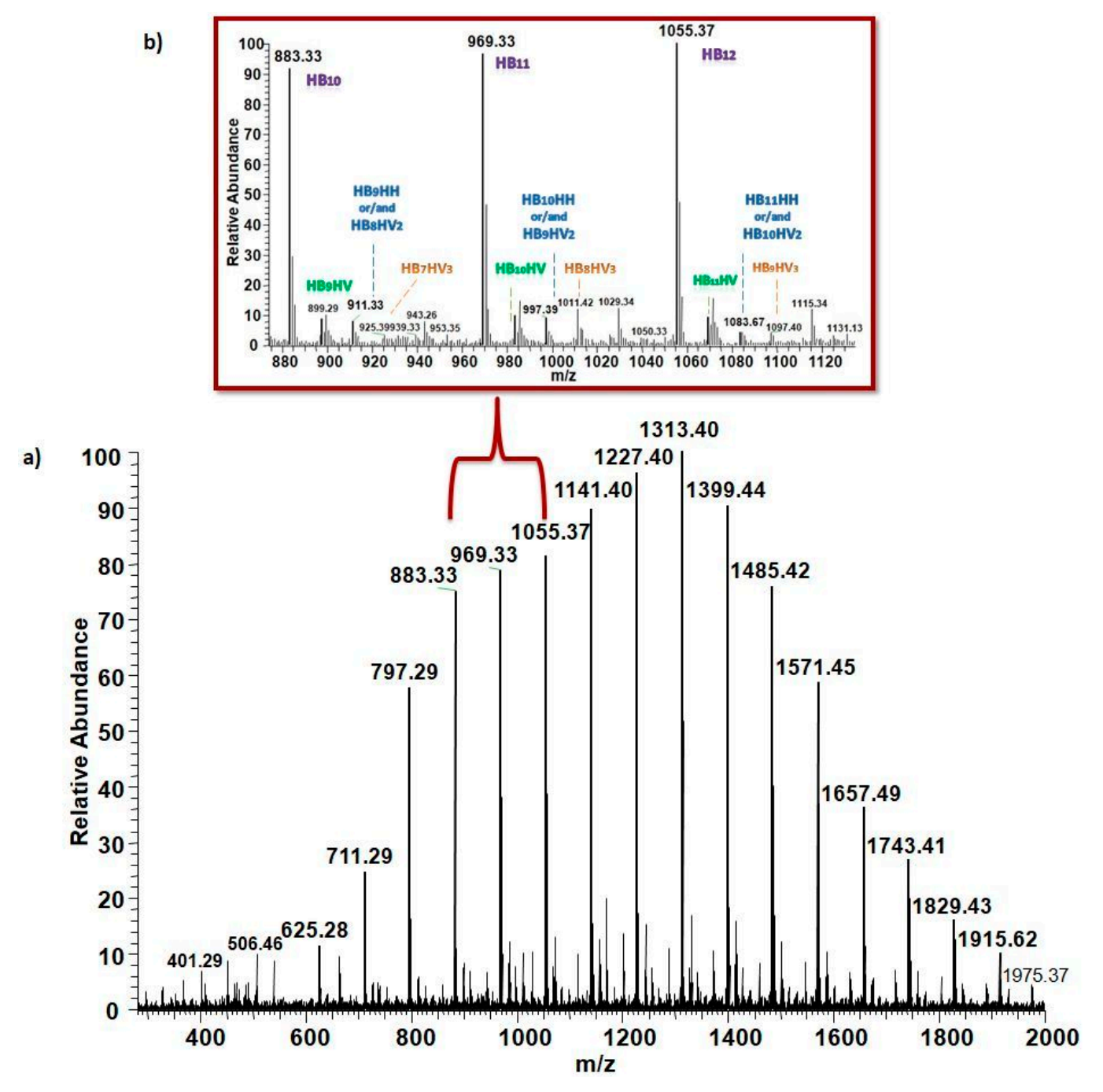

Figure 7. (a) The ESI-MS (positive-ion mode) of PHA oligomers formed after partial thermal degradation of sample PHA-PP-0; (b) spectral expansion in the mass range at $m / z$ 870-1140. The sample was analyzed in a chloroform/methanol $(1: 1 ; v / v)$ system. 


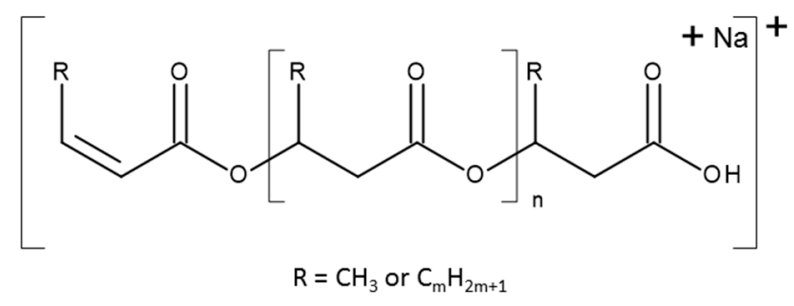

Scheme 1. The general chemical structure of the sodium adducts of PHA oligomers presented in the ESI-MS spectrum (Figure 7).

To verify the structural assignment of the ions present in the ESI-MS spectrum, in particular, to confirm the chemical structure of the end groups as well as the co-monomer sequence distribution (distribution of HA units along the oligomer chains) occurring in the PHA samples synthesized, dual-stage mass spectrometry (ESI-MS/MS) was applied. In this example, the ESI-MS/MS experiments for the ions belonging to the selected 11-mers cluster with nominal masses at $\mathrm{m} / \mathrm{z} 969,983$, and 997 were performed. Previously published studies of the fragmentation of individual PHA bio-polyester molecules revealed that the $\beta$-hydrogen rearrangement was the main mechanism inducing fragmentation of such polyesters via ester bond cleavage $[5,6,31,32]$. In the $\beta$-hydrogen transfer, the rearranged hydrogen is attached to the carbonyl oxygen, and this leads to cleavage of the alkyl-oxygen bond, resulting in the formation of two ions: one bearing a carboxylic acid end group and the other terminating with a crotonate group [33].

The ESI-MS/MS product ions spectrum for the selected sodium adduct of oligomer $\left[\mathrm{HB}_{11}+\mathrm{Na}\right]^{+}$ at $m / z 969$ is presented in Figure 8.
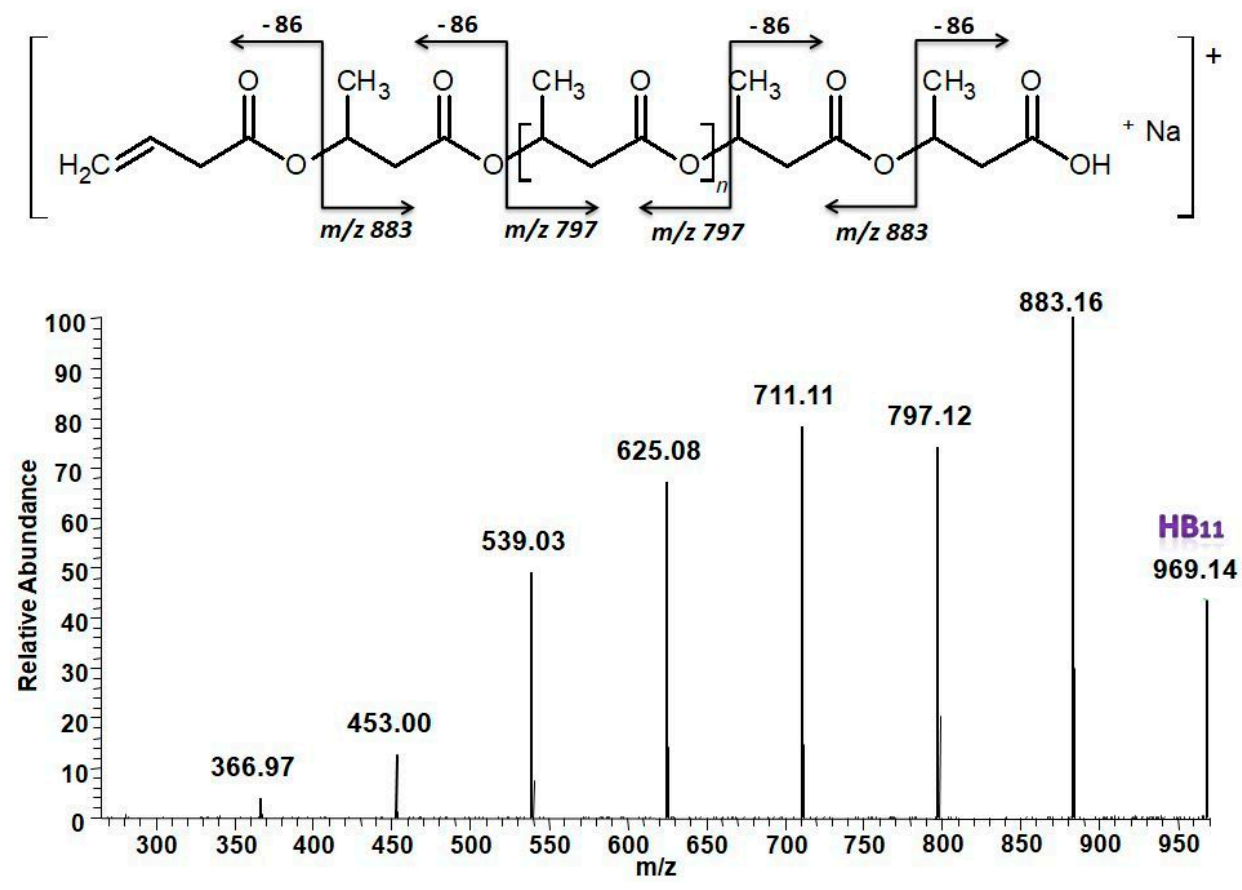

Figure 8. The ESI-MS/MS fragmentation spectrum of selected sodium adduct of $\left[\mathrm{HB}_{11}+\mathrm{Na}\right]^{+}$oligomers, at $m / z 969$ together with the theoretical fragmentation pattern.

The fragmentation of this ion, which resulted from the random breakage of ester bonds along the oligomer chain, led to the formation of only one set of oligo(3-hydroxybutyrate) product ions occurring at the values $\mathrm{m} / \mathrm{z}$ equal to $883,797,711,625,539,453$, and 367 , terminated by crotonate and carboxyl end groups. For example, the first ion from this series at $\mathrm{m} / \mathrm{z} 883 \mathrm{can}$ be produced by the cleavage of the ester bond and the loss of a neutral molecule of crotonic acid (86 Da), which can take place from both ends of the parent ion $\mathrm{m} / \mathrm{z}$ 969. The comparison of experimental ESI-MS/MS spectra with theoretical 
fragmentation patterns of this ion confirmed that the most intensive ion in this cluster corresponded to sodiated linear 3-hydroxybutyrate homopolymer chains built with the $11 \mathrm{HB}$ repeat units successively connected by ester bonds.

In Figure 9a,b, the ESI-MS/MS spectra of the selected parent sodium adducts of PHA oligomers at $m / z 983$ and at $m / z 997$ are shown.

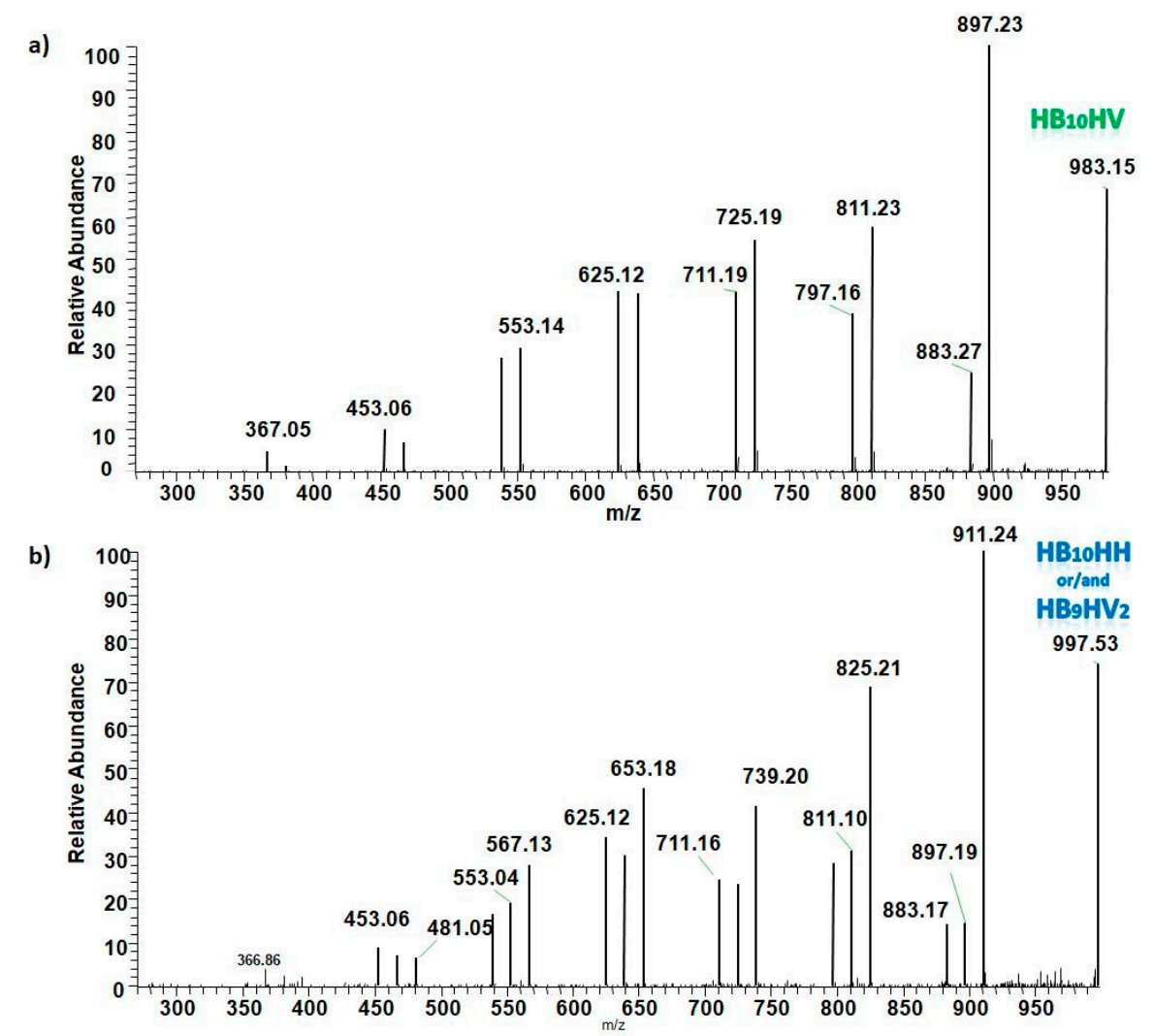

Figure 9. The ESI-MS/MS fragmentation spectra of selected sodium adducts of PHAs of $\left[\mathrm{HB}_{10} \mathrm{HV}+\right.$ $\mathrm{Na}]^{+}$oligomers at $m / z 983(\mathbf{a})$ and of $\left.\mathrm{HB}_{9} \mathrm{HV}_{2}+\mathrm{Na}\right]^{+}$or/and $\left[\mathrm{HB}_{10} \mathrm{HH}+\mathrm{Na}\right]^{+}$oligomers at $\mathrm{m} / \mathrm{z} 997(\mathbf{b})$.

Due to the random distribution of $\mathrm{HB}, \mathrm{HV}$, and $\mathrm{HH}$ units along the PHA co-oligomer chains, which yields the highest number of possible sequences in those oligomers, the spectra presented in Figure 9 are more complex than for the homopolymer presented in Figure 8. The fragment ions present in the MS/MS spectra (Figure 9a,b), which are formed via the random breakage of ester bonds along the oligomer chain, are grouped in clusters containing two fragment ions (in the case of $\left[\mathrm{HB}_{10} \mathrm{HV}+\right.$ $\mathrm{Na}]^{+}$or three fragment ions (in the case of a mixture of $\left[\mathrm{HB}_{10} \mathrm{HH}+\mathrm{Na}\right]^{+}$and/or $\left[\mathrm{HB}_{9} \mathrm{HV}_{2}+\mathrm{Na}\right]^{+}$). The individual clusters containing fragment ions with the same degree of oligomerization, but differing in chemical composition (different content of $\mathrm{HB}$ and $\mathrm{HV}$ units, or $\mathrm{HB}$ and $\mathrm{HH}$ units).

In the case of sodium adduct of $\left[\mathrm{HB}_{10} \mathrm{HV}+\mathrm{Na}\right]^{+}$oligomers, at $\mathrm{m} / \mathrm{z}=983$ the first cluster with two fragment anions at $\mathrm{m} / \mathrm{z} 897$ and $\mathrm{m} / \mathrm{z} 883$ can be produced by the cleavage of ester bonds and the losses of crotonic acid (86 Da) or 2-pentenoic acid (100 Da), respectively (Figure 9a). While in the case of the sodium adduct of $\left[\mathrm{HB}_{10} \mathrm{HH}+\mathrm{Na}\right]^{+}$or/and $\left[\mathrm{HB}_{9} \mathrm{HV}_{2}+\mathrm{Na}\right]^{+}$oligomers, at $\mathrm{m} / z=997$ the first clusters with three fragment anions at $m / z 911, \mathrm{~m} / \mathrm{z} 897$, and $\mathrm{m} / \mathrm{z} 883$ are produced by the cleavage of ester bonds and the losses of crotonic acid (86 Da), 2-pentenoic acid (100 Da), or 2-hexenoic acid (114), respectively (Figure $9 \mathrm{~b}$ ). The formation of the fragment ion with nominal mass $\mathrm{m} / \mathrm{z} 883$ clearly demonstrates the presence of the $\mathrm{HH}$ unit in the oligomer studied [5]. The theoretical fragmentation patterns of the selected sodiated $\left[\mathrm{HB}_{10} \mathrm{HV}+\mathrm{Na}\right]^{+}$oligomers, at $\mathrm{m} / z 983$ and $\left[\mathrm{HB}_{9} \mathrm{HV}_{2}+\mathrm{Na}\right]^{+}$or $\left[\mathrm{HB}_{10} \mathrm{HH}+\mathrm{Na}\right]^{+}$ oligomers at $m / z 997$ are presented in Schemes 2 and 3, respectively. 


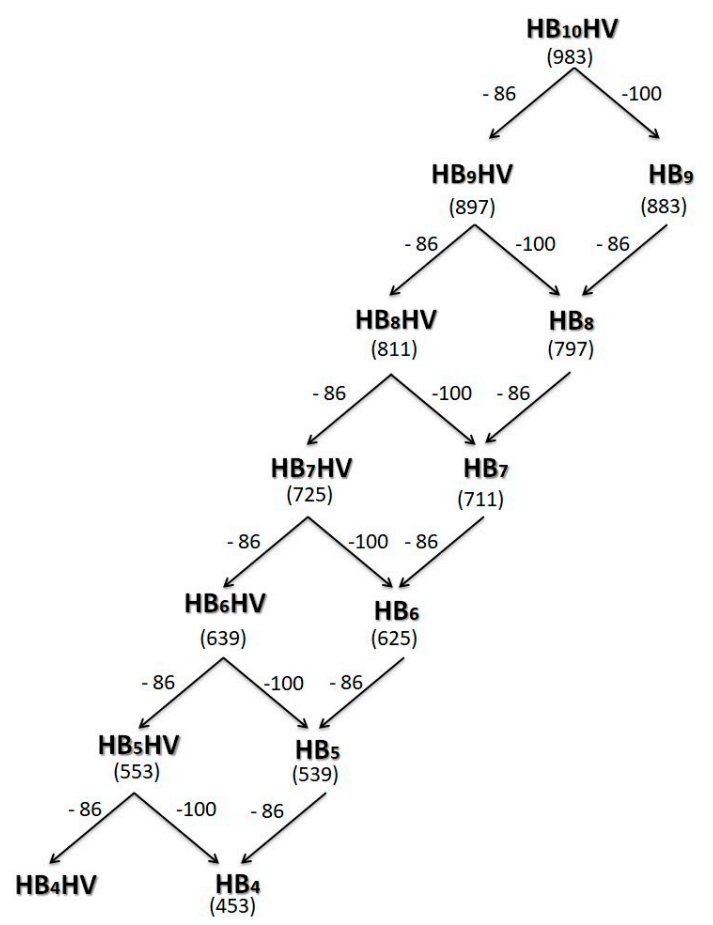

Scheme 2. The theoretical fragmentation patterns of the selected sodiated $\left[\mathrm{HB}_{10} \mathrm{HV}+\mathrm{Na}\right]^{+}$oligomers at $m / z 983$ Figure 9 a.
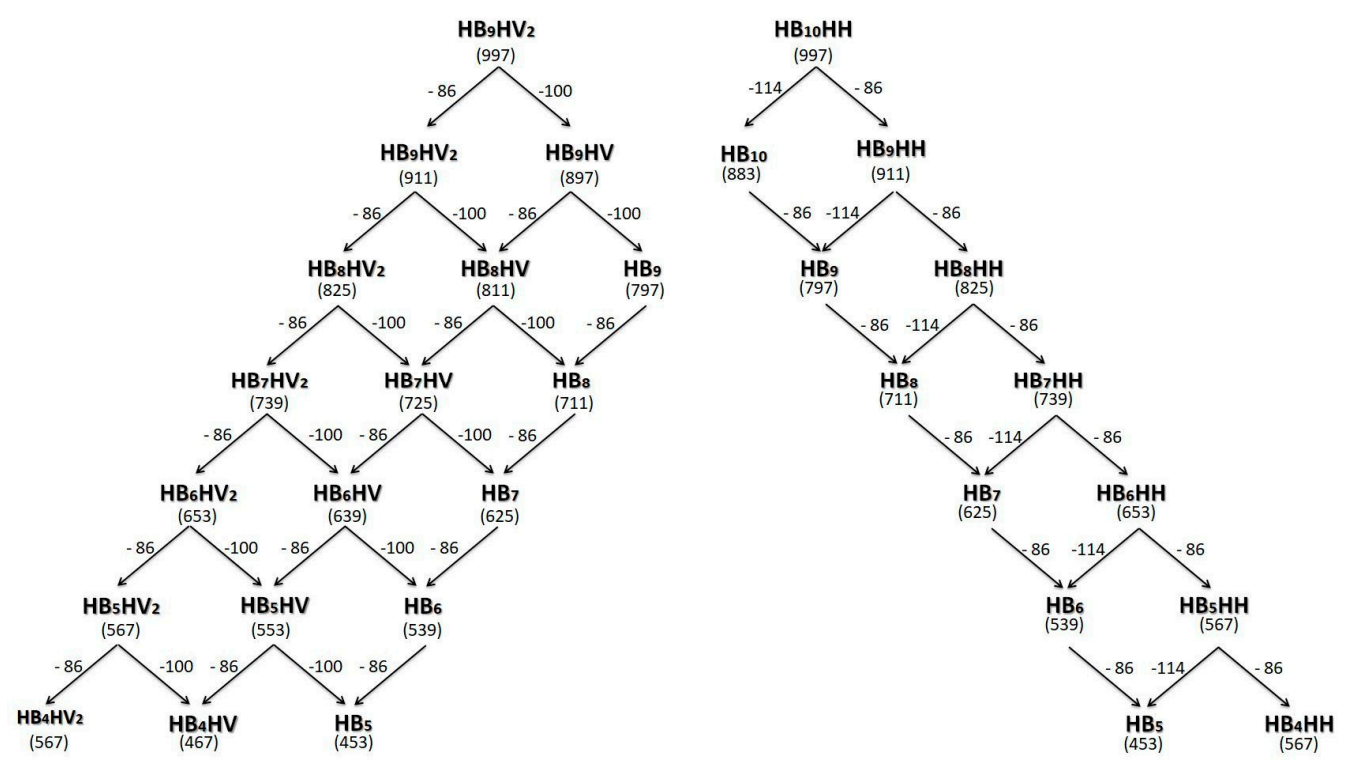

Scheme 3. The theoretical fragmentation patterns of the selected sodium adduct $\left[\mathrm{HB}_{9} \mathrm{HV}_{2}+\mathrm{Na}\right]^{+}$ or/and $\left[\mathrm{HB}_{10} \mathrm{HH}+\mathrm{Na}\right]^{+}$oligomers at $m / z 997$ (Figure $9 \mathbf{b}$ ).

The experimental mass spectra presented in Figures 8 and 9 confirmed that the resulting PHA samples were random copolymers that contained both the 3-HB homo-polyester molecules as well as 3-HB/HV and 3-HB/HH co-polyester molecules.

In order to verify the molecular structure of PHA derived from thermally treated prodegraded PP, the sample obtained via partial thermal degradation of PHA PP-2 was analyzed. The oligomer sample obtained contained the fraction which was dissolved in water. For structural characterization of this fraction, dual-stage electrospray mass spectrometry (ESI-MS/MS) was also applied and the acquired spectrum is presented in Figure 10. 


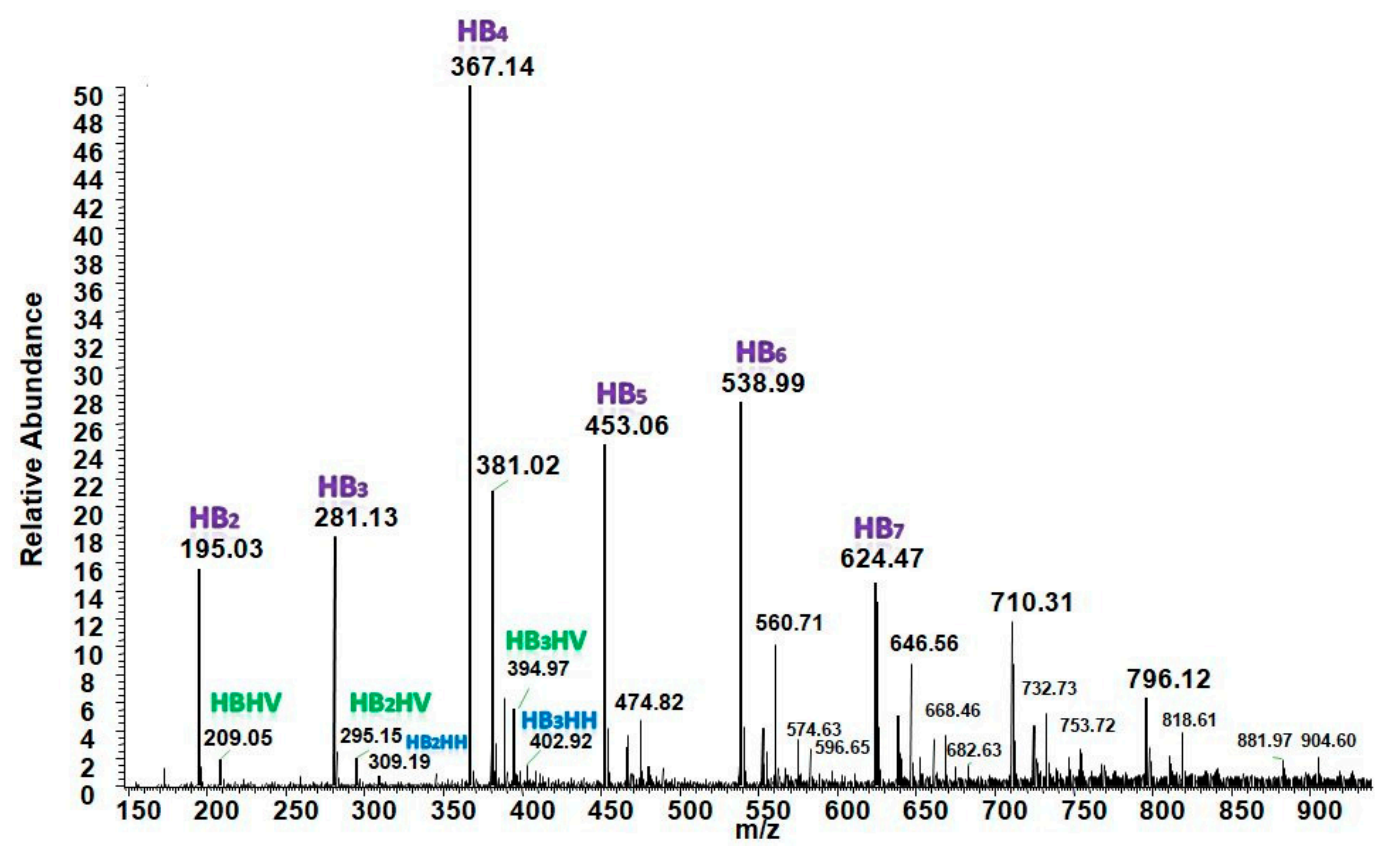

Figure 10. ESI-MS (positive-ion mode) of the water-soluble fraction of PHA oligomers formed after the partial thermal degradation of the PHA-PP2 sample.

The ESI-mass spectrum obtained for a water soluble fraction of the PHA oligomers is similar to that presented in Figure 7. The visible differences were connected with the mass range. The ESI-MS/MS spectra of the selected parent sodium adducts $\left[\mathrm{HB}_{4}+\mathrm{Na}\right]^{+}$at $m / z 367,\left[\mathrm{HB}_{3} \mathrm{HV}+\mathrm{Na}\right]^{+}$at $m / z 381$ and of the sodium adducts $\left[\mathrm{HB}_{2} \mathrm{HV}_{2}+\mathrm{Na}\right]^{+}$or $\left[\mathrm{HB}_{3} \mathrm{HH}+\mathrm{Na}\right]^{+}$oligomers at $m / z 395$ are present in Figure 11.<smiles>C=CCC(=O)OC(C)CC(=O)OC(C)(CC)CC(=O)OC(C)(CC)CC(=O)O</smiles>

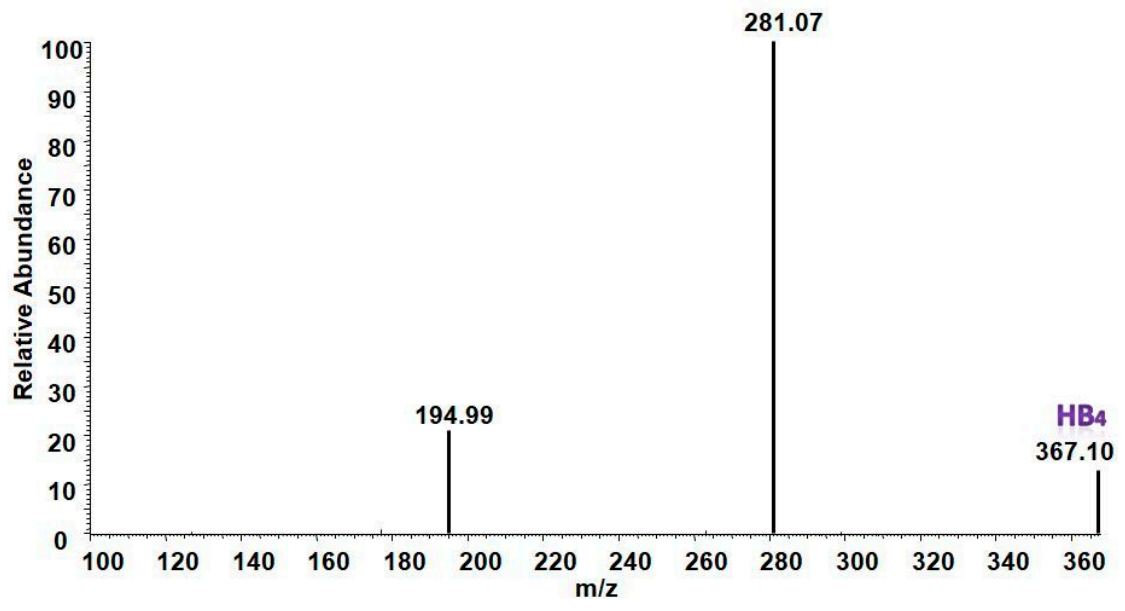

Figure 11. Cont. 

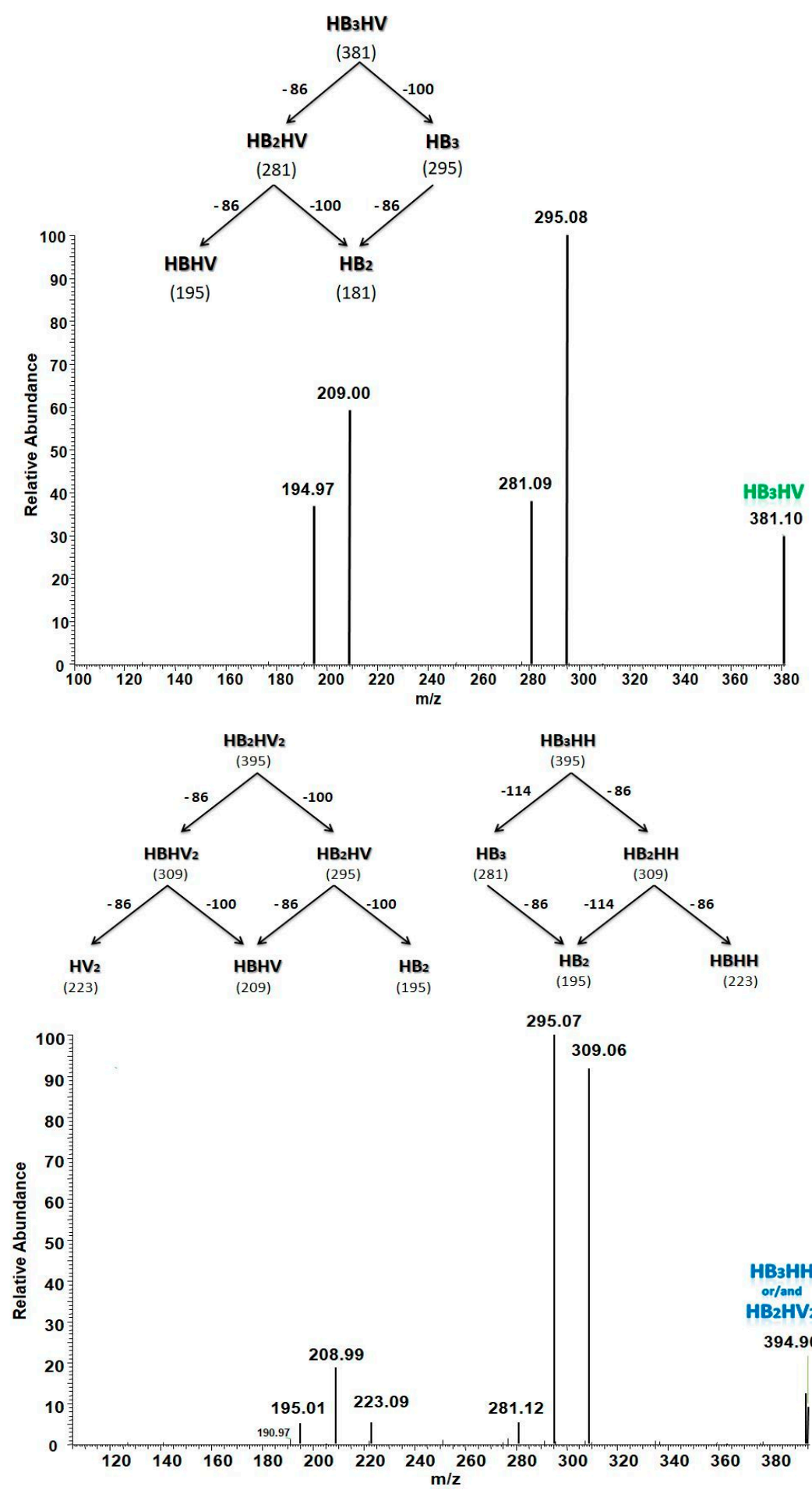

Figure 11. The ESI-MS/MS fragmentation spectra of the selected parent sodium adducts of $\left[\mathrm{HB}_{4}+\right.$ $\mathrm{Na}]^{+}$at $m / z 367,\left[\mathrm{HB}_{3} \mathrm{HV}+\mathrm{Na}\right]^{+}$at $m / z 381$, and $\left[\mathrm{HB}_{2} \mathrm{HV}_{2}+\mathrm{Na}\right]^{+}$or/and $\left[\mathrm{HB}_{3} \mathrm{HH}+\mathrm{Na}\right]^{+}$at $m / z 395$ oligomers selected from the ESI-mass spectrum in Figure 10.

The results of ESI-MS/MS fragmentation experiment performed for the selected ions, which represent the individual PHA oligoester chains, confirmed that the water-soluble fraction of PHA oligomers is also composed of both the 3-HB oligomers as well as 3- $\mathrm{HB} / \mathrm{HV}$ and 3-HB/HH co-oligoester oligomers. The formation of the fragment ion with nominal mass at $m / z 281$ clearly demonstrates the presence of a $\mathrm{HH}$ unit in the oligomer studied. 


\section{Discussion}

The originally reported utilization of pro-degraded PP as an additive carbon supplement in the bacterial production of PHA would give PP an extended usefulness life-span, as opposed to it adding to the current high levels of waste plastic pollution found around the globe, as discussed in the introduction. From the Table 1 results, PP-1 received the highest AN value in the thermal pretreatment with ozone at $60^{\circ} \mathrm{C}$ for $20 \mathrm{~h}$. This process does appear to have added ketone and aldehyde groups to the relatively saturated waste PP, making it a more facile carbon source for the shake flask procedure as seen in the growth curve (Figure 4). Although some of the other PP oxidized samples may have had more intense readings for ketone and aldehyde functional groups, the prolonged heat treatment is likely to have caused cross-linking structural changes that hindered bacterial uptake. The GPC data showed a decrease in the average molar mass of the PP specimens from PP-0 to PP-2, with PP-1 and PP-2 being equal at 2000 and seemingly being a good structural compromise for bacterial uptake.

As expected from the shake flask data, there was no production of PHAs when the minimal salt media and PP specimens were used as the sole carbon source. Again, from the FTIR and GPC results, the molecular size and hydrophilicity $(\mathrm{AN}=84.2)$ aids the absorption of PP-1 by bacteria into the $\beta$-oxidation pathway for PHA production, supporting the notion that it was the best carbon supplement developed in this study. From Figure 4 and Table 5, TSB and the addition of PP-0 to 2 did not have a negative effect on the growth of $C$. necator at $30^{\circ} \mathrm{C}$. Some previous experiments have shown that plastics like PE can have adverse growth effects on Gram-positive and Gram-negative bacteria $[34,35]$. The antimicrobial action of some plastics could be due to the presence of antimicrobial moieties such as fluorine or chlorine caught within the chains of the polymers. These elements could later be discharged in the midst of the thermal treatment process where they could then be released into the ambient growth media, altering overall cell proliferation [36]. PP-1 had the highest yield of PHA at $42 \%$, which was $20 \%$ higher than the TSB control results.

Proton NMR analysis was exploited in the assessment of the average structure across a whole sample of the copolymers synthesized for each PP carbon source. The ${ }^{1} \mathrm{H}-\mathrm{NMR}$ spectra of PHA-PPx showed the expected signals corresponding to the protons of 3-hydroxybutyrate (3-HB) and 3-hydroxyvalerate (3-HV) repeating units, which differed considerably from PHAs produced from TSB only. However, ESI-MS/MS was needed to determine the structure of the copolymers at the molecular level. This approach was included in the structural studies of PHAs produced from the pro-degraded PP, since a method is known to provide more details than ${ }^{1} \mathrm{H}$-NMR alone as it can corroborate whether copolymers are a co-block polymer or arbitrarily distributed [26]. The series of the cluster ions in the mass spectrum were sodium adducts derived from PHA with HB, HV, and $\mathrm{HH}$ chain units terminated by unsaturated and carboxylate groups. To further verify the PHA structure, the PHA-PP-0 and PHA-PP-2 samples were selected for dual MS studies and after their partial degradation, it was found that clusters with $\mathrm{HB}, \mathrm{HV}$, and $\mathrm{HH}$ repeat units with randomly distributed $\mathrm{HV}$ and $\mathrm{HH}$ units along the oligoester chains were formed.

The significance of the biopolymer structures of PHA obtained is that properties such as melting point or mechanical strength are changed, meaning that the applications of these bioplastics are different than that of the PHB homopolymer. PHAs are known to be marine biodegradable polymers and are easily broken-down by bacteria and fungi. Use of PHA for netting, packaging, or as an additive in 3D printing filaments creates opportunities for other uses in diverse marine applications, where biodegradation process gives an added value [37]. One of the additional reasons that PHA is such a good candidate for marine use, as opposed to traditional petrol-based plastics or PLA, is its rate of biodegradation in the ambient environment, because PLA, for example, needs a significant reduction in molar mass via hydrolysis before biodegradation can start [37].

\section{Conclusions}

To the best of our knowledge, we have originally reported the viability of using waste PP as an additional carbon source for the production of PHA, using an integrated approach that included 
bacterial shake flask procedures, FTIR, GPC, TGA, NMR, and ESI-MS/MS. In summary, the conditions needed to form viable PP as an additional carbon source were found. The PP-1 and PP-2 samples were found to be the most economically viable and treated PPx samples functioned as an additional carbon source to produce PHA copolymers that contained randomly distributed $\mathrm{HV}$ and $\mathrm{HH}$ repeat units along their PHA chains, as revealed by electrospray dual-stage mass spectrometry at the molecular level.

\section{Patents}

Partial degradation of PHA is a subject of an EU patent entitled: Process for Controlled Degradation of Polyhydroxyalkanoates and Products Obtainable there from. EP 2346922 B1. International publication number: WO 2010/044112 (22.04.2010 Gazette 2010/16). Date of filing: 15.10.2008. Date of publication of application: 27.07.2011.

Author Contributions: E.C., D.B., and V.I.I. were responsible for providing the original PP sample. A.A.M. conducted the pretreatment of PP samples to produce PP-1 and PP-2. B.J., A.I.E., and I.R. were responsible for the bacterial production of PHA and PHA initial characterization. B.J. and B.M. were responsible for GPC analysis. G.A., M.Z., P.C., W.S., M.M., and M.K. were responsible for PP and PHA characterizations using TGA and ESI-MS/MS. M.K., B.J., G.A., and I.R. were the main people involved in the planning of the experiments and interpretation of the data of PHA characterization.

Funding: This research was funded by the Research Investment Fund, University of Wolverhampton, Faculty of Science and Engineering, UK. This work was also partially supported the European Regional Development Fund Project EnTRESS No 01R16P00718 and the PELARGODONT Project UM0-2016/22/Z/STS/00692 financed under the M-ERA.NET 2 Program of Horizon 2020.

Acknowledgments: We would like to take this opportunity to thank Professor Emo Chiellini for inspiring this work and his input throughout the writing process. In addition, we would also like to thank Leighton Thomas and Chris Mason-Parker for the image of waste plastic on a beach in Ambon, Indonesia.

Conflicts of Interest: The authors declare no conflict of interest.

\section{References}

1. Yol, A.M.; Janoski, J.; Quirk, R.P.; Wesdemiotis, C. Sequence Analysis of Styrenic Copolymers by Tandem Mass Spectrometry. Anal. Chem. 2014, 86, 9576-9582. [CrossRef] [PubMed]

2. Barner-Kowollik, C.; Gründling, T.; Falkenhagen, J.; Weidner, S. Mass Spectrometry in Polymer Chemistry; Wiley-VCH: Weinheim, Germany, 2011.

3. Kowalczuk, M.; Adamus, G. Mass spectrometry for the elucidation of the subtle molecular structure of biodegradable polymers and their degradation products. Mass Spectrom. Rev. 2016, 35, 188-198. [CrossRef] [PubMed]

4. Adamus, G.; Sikorska, W.; Kowalczuk, M.; Montaudo, M.; Scandola, M. Sequence Distribution and Fragmentation Studies of Bacterial Copolyester Macromolecules: Characterization of PHBV Macroinitiator by Electrospray Ion-Trap Multistage Mass Spectrometry. Macromolecules 2000, 33, 5797-5802. [CrossRef]

5. Adamus, G.; Sikorska, W.; Kowalczuk, M.; Noda, I.; Satkowski, M.M. Electrospray ion-trap multistage mass spectrometry for characterisation of co-monomer compositional distribution of bacterial poly(3-hydroxybutyrate-co-3-hydroxyhexanoate) at the molecular level. Rapid Commun. Mass Spectrom. 2003, 17, 2260-2266. [CrossRef] [PubMed]

6. Adamus, G. Molecular Level Structure of (R,S)-3-Hydroxybutyrate/(R,S)-3-Hydroxy-4-ethoxybutyrate Copolyesters with Dissimilar Architecture. Macromolecules 2009, 42, 4547-4557. [CrossRef]

7. Maddah, H.A. Polypropylene as a promising plastic: A review. Am. J. Polym. Sci. 2016, 6, 1-11.

8. LeBlanc, R. Polypropylene Recycling-An Introduction. Available online: https://www.thebalancesmb.com/ an-overview-of-polypropylene-recycling-2877863 (accessed on 9 August 2019).

9. Thompson, R.C.; Swan, S.H.; Moore, C.J.; Vom Saal, F.S. Our plastic age. Philos. Trans. R. Soc. Lond. B Biol. Sci. 2009, 364, 1973-1976. [CrossRef] [PubMed]

10. United States Environmental Protection Agency. Plastics: Material-Specific Data. Available online: https: //www.epa.gov/facts-and-figures-about-materials-waste-and-recycling/plastics-material-specific-data (accessed on 9 August 2019). 
11. United Nations Environment Programme. Marine Plastic: A New and Growing Threat to Coral Reefs. Available online: http://www.unenvironment.org/news-and-stories/story/marine-plastic-new-and-growingthreat-coral-reefs (accessed on 9 August 2019).

12. Lamb, J.B.; Willis, B.L.; Fiorenza, E.A.; Couch, C.S.; Howard, R.; Rader, D.N.; True, J.D.; Kelly, L.A.; Ahmad, A.; Jompa, J.; et al. Plastic waste associated with disease on coral reefs. Science 2018, 359, 460-462. [CrossRef]

13. Kirstein, I.V.; Kirmizi, S.; Wichels, A.; Garin-Fernandez, A.; Erler, R.; Löder, M.; Gerdts, G. Dangerous hitchhikers? Evidence for potentially pathogenic Vibrio spp. on microplastic particles. Mar. Environ. Res. 2016, 120, 1-8. [CrossRef] [PubMed]

14. Pollock, F.J.; Wada, N.; Torda, G.; Willis, B.L.; Bourne, D.G. White Syndrome-Affected Corals Have a Distinct Microbiome at Disease Lesion Fronts. Appl. Environ. Microbiol. 2016, 83, e02799-16. [CrossRef]

15. Burke, L.; Reytar, K.; Spalding, M.; Perry, A. Reefs at Risk Revisted. Available online: http://pdf.wri.org/ reefs_at_risk_revisited_coral_triangle (accessed on 27 October 2018).

16. Somleva, M.N.; Peoples, O.P.; Snell, K.D. PHA bioplastics, biochemicals, and energy from crops. Plant Biotechnol. J. 2013, 11, 233-252. [CrossRef] [PubMed]

17. Johnston, B.; Jiang, G.; Hill, D.; Adamus, G.; Kwiecień, I.; Zięba, M.; Sikorska, W.; Green, M.; Kowalczuk, M.; Radecka, I. The Molecular Level Characterization of Biodegradable Polymers Originated from Polyethylene Using Non-Oxygenated Polyethylene Wax as a Carbon Source for Polyhydroxyalkanoate Production. Bioengineering 2017, 4, 73. [CrossRef] [PubMed]

18. Koller, M. Biodegradable and Biocompatible Polyhydroxy-alkanoates (PHA): Auspicious Microbial Macromolecules for Pharmaceutical and Therapeutic Applications. Molecules 2018, 23, 362. [CrossRef] [PubMed]

19. Aldas, M.; Paladines, A.; Valle, V.; Pazmiño, M.; Quiroz, F. Effect of the Prodegradant-Additive Plastics Incorporated on the Polyethylene Recycling. Available online: https://www.hindawi.com/journals/ijps/2018/ 2474176/ (accessed on 9 August 2019).

20. Johnston, B.; Radecka, I.; Hill, D.; Chiellini, E.; Ilieva, V.I.; Sikorska, W.; Musioł, M.; Zięba, M.; Marek, A.A.; Keddie, D.; et al. The Microbial Production of Polyhydroxyalkanoates from Waste Polystyrene Fragments Attained Using Oxidative Degradation. Polymers 2018, 10, 957. [CrossRef] [PubMed]

21. Malykh, N.; Petrov, V.; Mal'tzev, L.I. Ultrasonic and Hydrodynamic Cavitation and Liquid Hydrocarbon Cracking. XX Sess. Russ. Acoust. Soc. 2008, 10, 345-348.

22. Adamus, G.; Kwiecień, I.; Maksymiak, M.; Bałakier, T.; Jurczak, J.; Kowalczuk, M. Molecular level structure of novel synthetic analogues of aliphatic biopolyesters as revealed by multistage mass spectrometry. Anal. Chim. Acta 2014, 808, 104-114. [CrossRef] [PubMed]

23. Adamus, G.; Kowalczuk, M. Anionic Ring-Opening Polymerization of $\beta$-Alkoxymethyl-Substituted $\beta$-Lactones. Biomacromolecules 2008, 9, 696-703. [CrossRef] [PubMed]

24. Adamus, G. Structural analysis of poly[(R,S)-3-hydroxybutyrate-co-L-lactide] copolyesters by electrospray ionization ion trap mass spectrometry. Rapid Commun. Mass Spectrom. 2007, 21, 2477-2490. [CrossRef]

25. Kawalec, M.; Janeczek, H.; Adamus, G.; Kurcok, P.; Kowalczuk, M.; Scandola, M. The Study of Kinetics of Poly[(R,S)-3-hydroxybutyrate) Degradation Induced by Carboxylate. Macromol. Symp. 2008, 272, 63-69. [CrossRef]

26. Wei, L.; Guho, N.M.; Coats, E.R.; McDonald, A.G. Characterization of poly(3-hydroxybutyrate-co-3hydroxyvalerate) biosynthesized by mixed microbial consortia fed fermented dairy manure. J. Appl. Polym. Sci. 2014, 131. [CrossRef]

27. Miles, A.A.; Misra, S.S.; Irwin, J.O. The estimation of the bactericidal power of the blood. J. Hyg. 1938, 38, 732-749. [CrossRef]

28. Kawalec, M.; Sobota, M.; Scandola, M.; Kowalczuk, M.; Kurcok, P. A convenient route to PHB macromonomers via anionically controlled moderate-temperature degradation of PHB. J. Polym. Sci. Part Polym. Chem. 2010, 48, 5490-5497. [CrossRef]

29. Barbeş, L.; Rădulescu, C.; Stihi, C. ATR-FTIR Spectrometry Characterisation of Polymeric Materials. Romanian Rep. Phys. 2014, 66, 765-777.

30. Shamala, T.R.; Divyashree, M.S.; Davis, R.; Kumari, K.S.L.; Vijayendra, S.V.N.; Raj, B. Production and characterization of bacterial polyhydroxyalkanoate copolymers and evaluation of their blends by fourier transform infrared spectroscopy and scanning electron microscopy. Indian J. Microbiol. 2009, 49, 251-258. [CrossRef] 
31. Adamus, G. Aliphatic Polyesters for Advanced Technologies-Structural Characterization of Biopolyesters with the Aid of Mass Spectrometry. Macromol. Symp. 2006, 239, 77-83. [CrossRef]

32. Žagar, E.; Kržan, A.; Adamus, G.; Kowalczuk, M. Sequence Distribution in Microbial Poly(3-hydroxybutyrateco-3-hydroxyvalerate) Co-polyesters Determined by NMR and MS. Biomacromolecules 2006, 7, 2210-2216. [CrossRef]

33. Jedliński, Z.; Adamus, G.; Kowalczuk, M.; Schubert, R.; Szewczuk, Z.; Stefanowicz, P. Electrospray tandem mass spectrometry of poly(3-hydroxybutanoic acid) end groups analysis and fragmentation mechanism. Rapid Commun. Mass Spectrom. 1998, 12, 357-360. [CrossRef]

34. Rametsteiner, G.; Rametsteiner, K.; Kern, W. Polyethylene compounds with antimicrobial surface properties. Eur. Polym. J. 2006, 42, 3383-3389.

35. Zhang, W.; Luo, Y.; Wang, H.; Jiang, J.; Pu, S.; Chu, P.K. Ag and Ag/N2 plasma modification of polyethylene for the enhancement of antibacterial properties and cell growth/proliferation. Acta Biomater. 2008, 4, 2028-2036. [CrossRef]

36. McDonald, G.R.; Hudson, A.L.; Dunn, S.M.J.; You, H.; Baker, G.B.; Whittal, R.M.; Martin, J.W.; Jha, A.; Edmondson, D.E.; Holt, A. Bioactive Contaminants Leach from Disposable Laboratory Plasticware. Science 2008, 322, 917. [CrossRef]

37. Dudek, S.; Coskun, M.C. Biopolymer Compounds for Applications Requiring Marine Degradation. Presented at ANTEC Anaheim 2017, Anaheim, CA, USA, 8-10 May 2017; p. 415.

(C) 2019 by the authors. Licensee MDPI, Basel, Switzerland. This article is an open access article distributed under the terms and conditions of the Creative Commons Attribution (CC BY) license (http://creativecommons.org/licenses/by/4.0/). 